\title{
Photovoltaics Effective Capacity Interim Final Report 2
}

R. Perez and R. Seals Atmospheric Sciences Research Center The University at Albany

NREL technical monitor: C. Herig

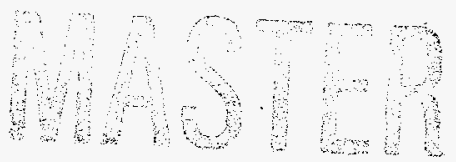

National Renewable Energy Laboratory 1617 Cole Boulevard Golden, Colorado 80401-3393 A national laboratory of the U.S. Department of Energy Managed by Midwest Research Institute for the U.S. Department of Energy under Contract No. DE-AC36-83CH10093

Prepared under Subcontract No. XR-1-11168-1

November 1997 
This publication was reproduced from the best available camera-ready copy submiled by the subcontractor and received no editorial review at NREL.

\section{NOTICE}

This report was prepared as an account of work sponsored by an agency of the United S:ates govemment. Neither the United States govemment nor any agency thereor, nor any of their emplcyees, makes any warranty, express or implied, or assumes any legal liability or responsibility for the accuracy, completeness, or usefulness of any information, apparatus, product, or process disclosed, or represents that its use would not infringe privately owned rights. Reference herein to any specific commercial product, process, or service by trade name, trademark, manufacturer, or otherwise does not necessarily consitute or imply its endorsement, recommendation, or favoring by the United States govemment or any agency thereof. The views and opinions of authors expressed herein do not necessarily state or reflect those of the United States government or any agency thereof.

Available to DOE and DOE contractors from:

Office of Scientific and Technical Information (OSTI)

P.O. Box 62

Oak Ridge, TN 37831

Prices available by calling (423) 576-8401

Available to the public from:

National Technical Information Service (NTIS)

U.S. Deparment of Commerce

5285 Port Royal Road

Springfield, VA 22161

(703) $487-4650$ 


\section{DISCLAMMER}

Portions of this document may be illegible in electronic image products. Images are produced from the best available original documert. 


\section{TABLE OF CONTENTS}

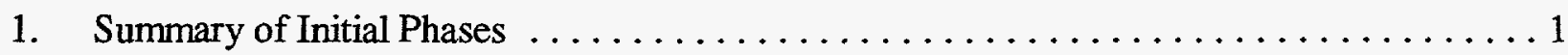

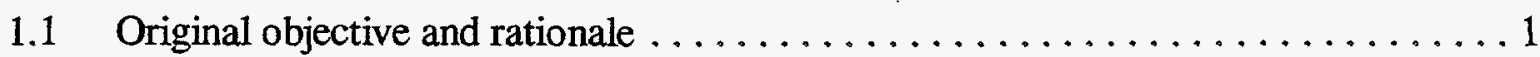

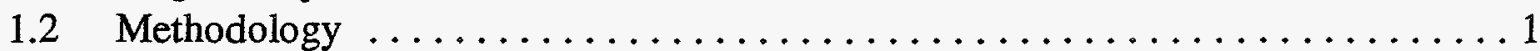

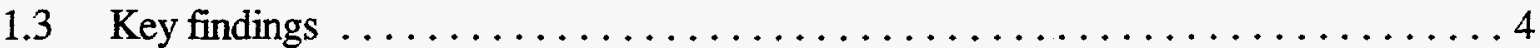

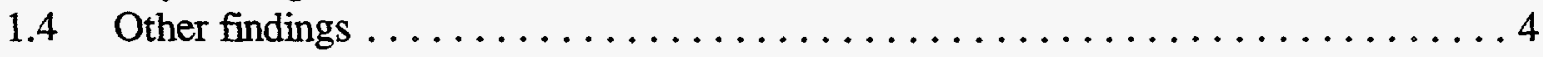

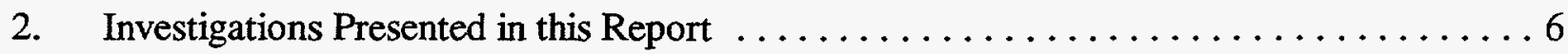

3. Experimental Determination of Effective Capacity $\ldots \ldots \ldots \ldots \ldots \ldots \ldots \ldots \ldots \ldots$

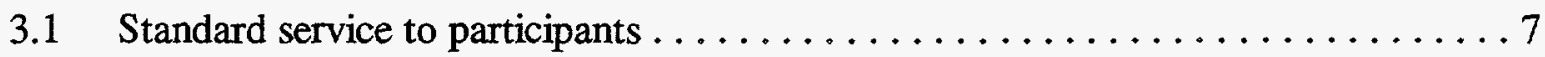

3.2 Current status on experimental loads $\ldots \ldots \ldots \ldots \ldots \ldots \ldots \ldots \ldots \ldots$

3.3 Overview of effective capacity determination results $\ldots \ldots \ldots \ldots \ldots \ldots$

3.4 Impact of solar resource and load characteristics on effective capacity . . . . . . 11

3.5 Parameterizing the impact of PV configuration and PV penetration on

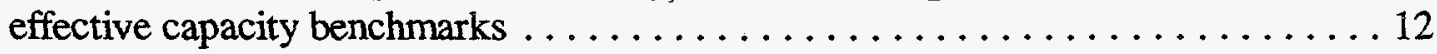

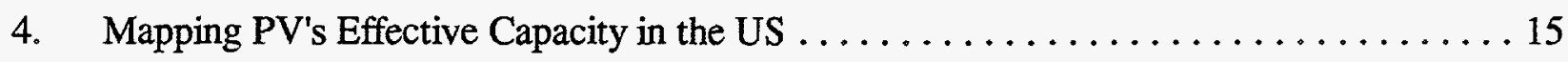

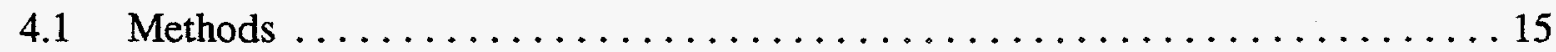

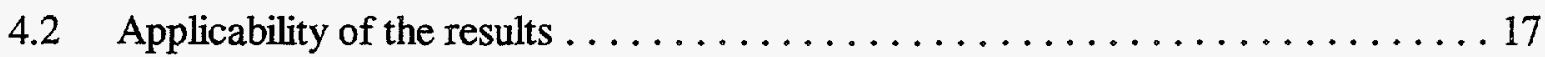

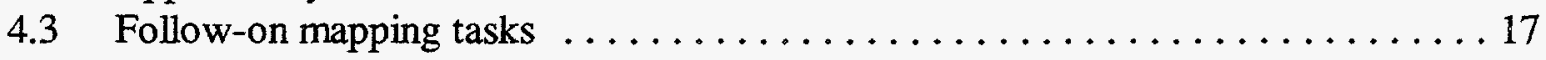

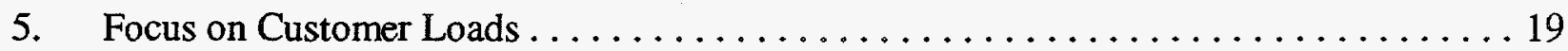

5.1 Validation of load shape-effective capacity relationships for small loads . . . . 19

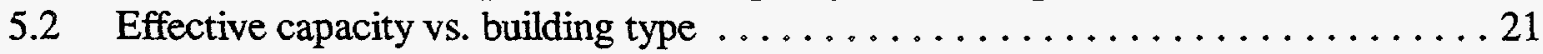

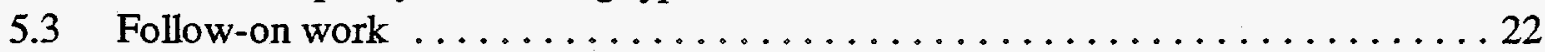

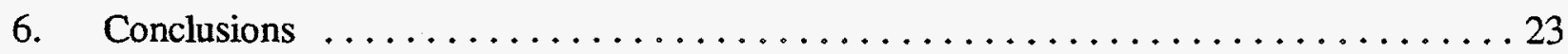

Attachment No. 1

Geographical Distribution of Photovoltaic Effective Capacity in the United States . . . . 25

Attachment No. 2

Estimating Market Potential for Reducing Customer Peak Loads

through Photovoltaics 


\section{SUMMARY OF INITIAL PHASES}

\subsection{Original objective and rationale}

The original objective of this project was to estimate the effective capacity of PV for a representative sample of US utilities. The effective capacity of a power generator is its ability to effectively contribute to the capacity available to a utility or a sub-utility (e.g., a substation) to meet its load requirements. Note at this time that the term capacity factor is largely unrelated to effective capacity, as it simply expresses the ratio of the average system output over its rated output.

Because PV generation is not controllable/dispatchable, it has traditionally been considered strictly as an energy source and been given no capacity allowance. However, because load drivers are often sun-synchronous, the effective capacity of PV may be considerable.

The economic implications of knowing PV's effective capacity are non trivial: Besides the traditional utility-wide capacity value (often limited today because of prevalent overcapacity), localized effective capacity is a key condition to most transmission and distribution benefits [e.g., see 1, 2]. From a customer PV ownership standpoint, effective capacity translates into effective demand reduction [e.g., 3].

\subsection{Methodology}

\section{Quantifying Effective Capacity}

One of our first tasks was to define the parameters needed to measure and compare effective capacity. Four benchmark parameters were defined and are briefly described below:

- $\quad$ ELCC (Normalized Effective Load Carrying Capacity). This parameter provides a statistical measure of effective capacity [see 4, 5]. It measures the effective increase in capacity available to a utility (or a sub-utility) due to the addition of PV, at constant loss-of-load probability (LOLP). ELCC is dependent on the penetration of PV with respect to the considered load; we consider penetration levels ranging from 1 to $20 \%$.

- MBES (Minimum Buffer Energy Storage). This parameter is a measure of the minimum amount of backup energy necessary, in addition to the PV system, to guarantee that all loads above a given threshold are met by the PV system $[5,6]$. Unlike the ELCC which provides a statistical measure of PV capacity, the MBES provided a tangible "worse case" measure of capacity. MBES is calculated for different thresholds ranging from $99 \%$ of peak load down to $80 \%$ (i.e., equivalent to PV penetration ranging from 1 to 20\%). The MBES is compared to the TES (Total Energy Storage) that would be needed without PV to meet all load above the same threshold. 
- $\quad \boldsymbol{P M P R}$ (Probability of maximum peak reduction). This is a probabilistic measure of PV capacity, reporting the mean PV output for the top 10, 25, 50, 100, etc. hourly loads.

- $\quad M E W$ (Mean energy worth). This is another probabilistic measure of PV, based on the distribution of PV output as a function of load requirements. The MEW is calculated by assigning a nominal energy value scale ranging from 1 , for the bottom $10 \%$ loads, to 10 , for the top $10 \%$ loads.

All effective capacity benchmarks are quantified in relation to the Mean Summer ACPV rating, and are calculated for both 2-axis tracking and fixed (at latitude - $10^{\circ}$ ) PV configurations.

\section{Experimental Data Requirements -- Use of Satellite Remote Sensing}

The experimental data necessary to determine any of the above benchmarks consist of a statistically significant set (one year) of time/site coincident hourly (or higher frequency) PV and load data. Load data are often available from utility archives and PV output can be adequately simulated from irradiance data.

However, site/time specific irradiance data are only rarely available. We circumvented the problem by using geostationary satellite remote sensing as a source of site/time specific irradiances for arbitrary locations. Geostationary satellites offer a space/time continuous monitoring of the earth cloud cover and each pixel can be considered as a solar monitoring station (see Fig. 1 and 2 [respectively from 7 and 8]).

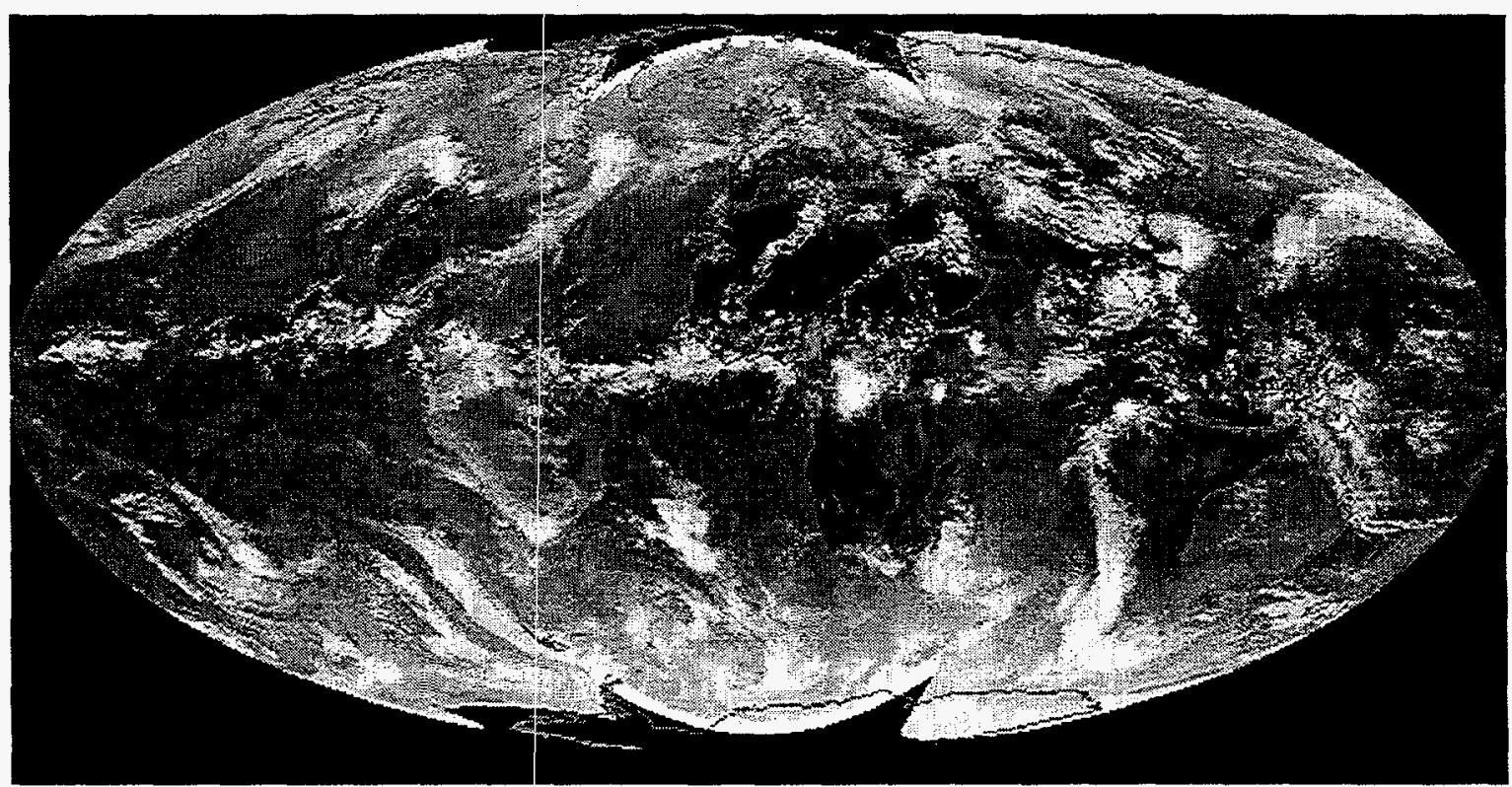

Fig.1: Composite view of GOES 8, Meteosat and GMS geostationary satellites illustrating the space/time continuous monitoring of the earth cloud cover (composite image from [7]) 
Although they are inherently less accurate than ground measurements, satellite derived hourly irradiances are the most accurate source of time/site specific data when the distance from a ground station exceeds $27 \mathrm{~km}$ (16 miles) as shown by a recent investigation by the authors (see Fig. 3 [from 8]).

For the present study, we took advantage of satellite irradiances pre-processed by NOAA-NESDIS [9] on a $1^{\circ}$ latitude-longitude grid (about $100 \times 75 \mathrm{~km}$ in the US) for 1987 and 1988.

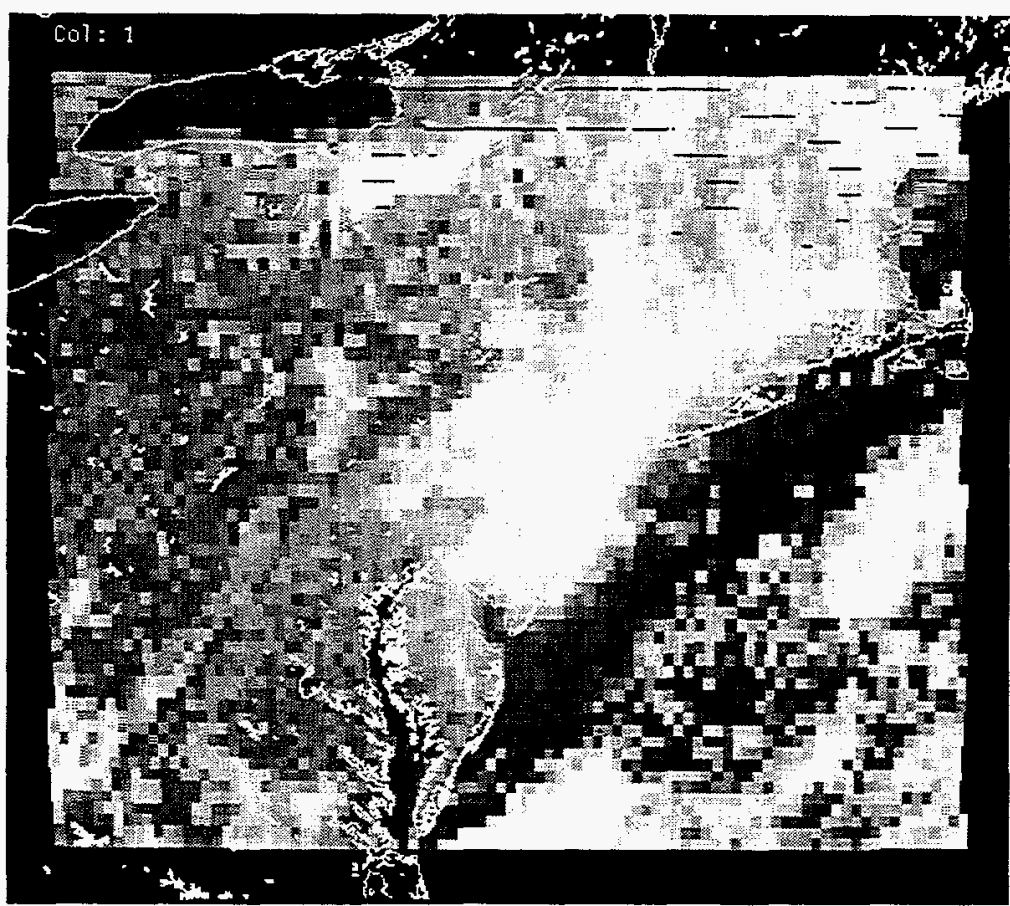

Fig. 2: Example of intermediate resolution image from GOES 8.

Frames covering the northeastern US -- Note Lake Ontario at top left and Delmarva Peninsula at bottom center -- are currently acquired at our Research Center. Each pixel may be considered a solar monitoring station [8]

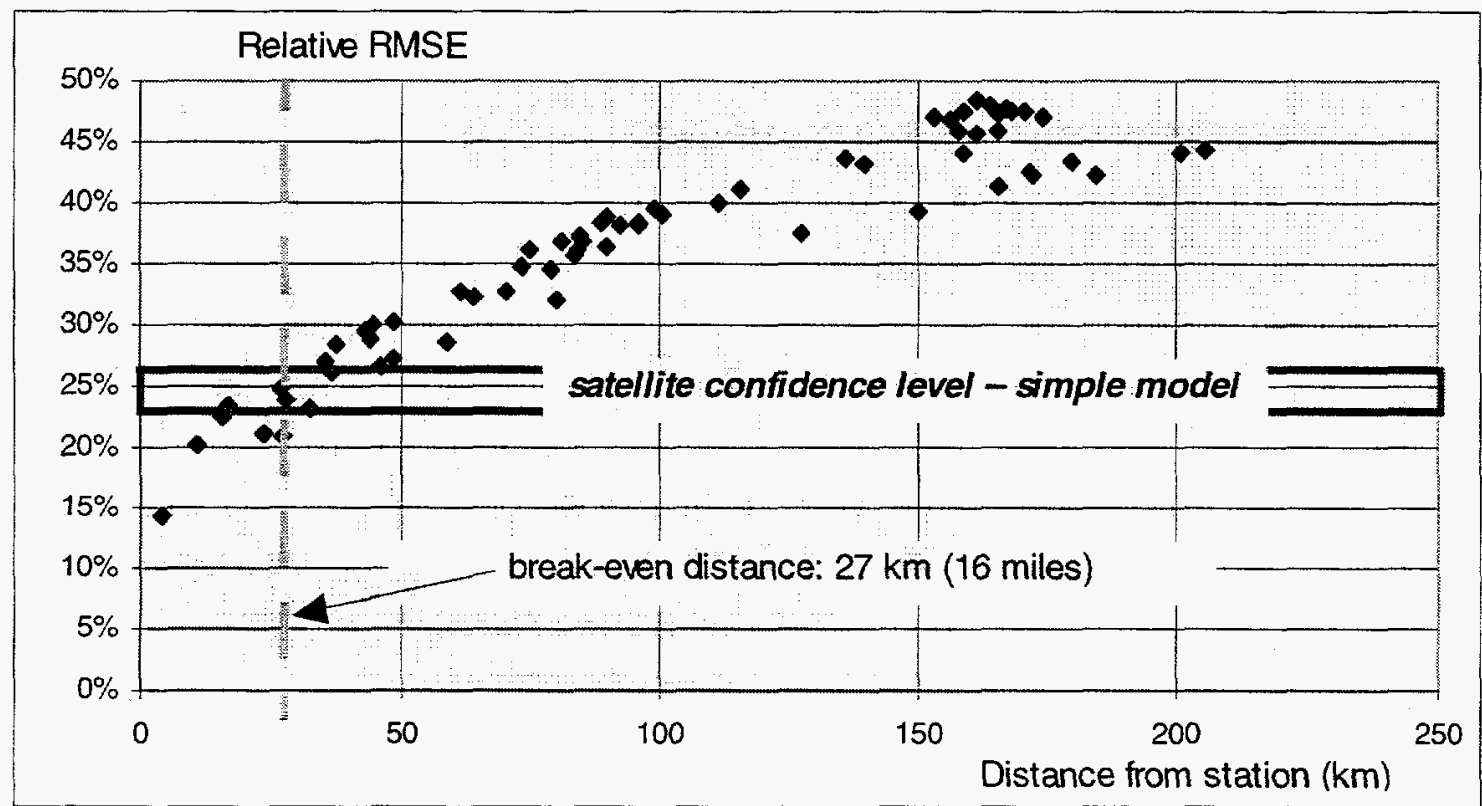

Fig. 3: Deterioration of accuracy of time/site specific global irradiance as a function of distance from measuring station compared to satellite accuracy (from [8]) 


\subsection{Key findings}

PV Capacity may be significant outside traditional solar regions: PV effective capacity was found to be significant for several utilities not located in "traditional solar regions. Utilities in the Central US and on the eastern seaboard were found to have ELCCs of $70 \%$ or more, often in excess of utilities located in the southwest and Florida.

Effective capacity is not correlated well with the solar resource: Upon analysis of a significant number of loads throughout the US, effective capacity was not found to be well correlated with the solar resource (see Fig. 15 in Section 3.4 below).

Effective capacity is correlated with load shape characteristics: PV's effective capacity was found to be a strong function of load shape parameters, chiefly, the ratio of summerto-winter peak load (see Fig. 16 in Section 3.4 below).

These findings are described in detail in [5, 10 and 11]

\subsection{Other Findings}

Representativeness of experimental data: Since our analysis was based on two years of data, 1987 and 1988, the question was posed whether solar resource may have been anomalous for this time period. After looking at 30 years of data at 50 sites (source instrumented NSRDB sites [12]), we concluded that 1987 and 1988 did not largely depart from the long term means in any regions of the US. Both years were representative of clean atmospheric conditions (i.e., not affected by major volcanic eruptions) and, as such, were slightly above the long term mean. More importantly, we found that insolation differences between 1987 and 1988 had no detectable impact on the determination of $P V ' s$ effective capacity. This investigation is detailed in [13].

Daily irradiances may be acceptable for a preliminary assessment of PV effective capacity: Because daily irradiances are more commonly available than hourly irradiances, we investigated the impact of using daily irradiance input on the determination of effective capacities. Synthesized hourly data (constant clearness index) were derived from the daily irradiance input and analyzed against the hourly load data. Results using the daily input were found to

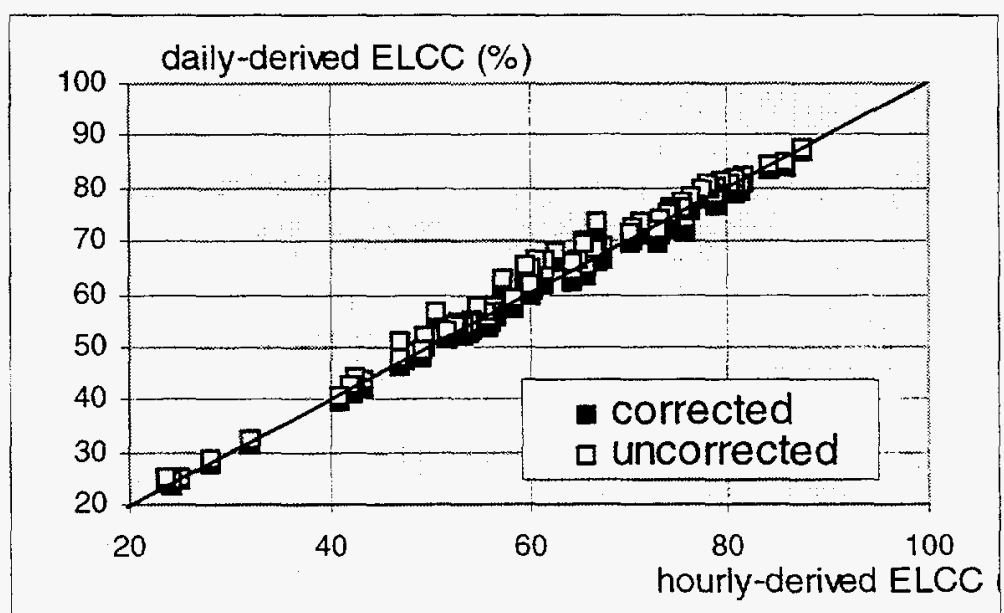

Fig. 4: Uncorrected and empirically corrected daily-derived ELCC vs. hourly derived ELCC. 
match the hourly-derived results rather well especially for statistical benchmarks such as the ELCC (see Fig. 4) where a simple empirical correction brought the results close to the 1-1 line. This empirical correction is

$$
E L C C_{d c}=f * E L C C_{d u},
$$

where $E L C C_{d c}$ is the corrected daily-derived ELCC, $E L C C_{d u}$ is the uncorrected dailyderived value. The function $f$ is

$$
\begin{aligned}
& f=0.965 * E L C C_{d u}, \text { if } E L C C_{d u}<75 \%, \text { and } \\
& f=0.775+0.0025 * E L C C_{d u}, \text { otherwise. }
\end{aligned}
$$

The match was still acceptable, but not as convincing in the case of the deterministic MBES benchmark, which is considerably more sensitive to late-afternoon cloudiness (see Fig. 5). This investigation is discussed in [14].

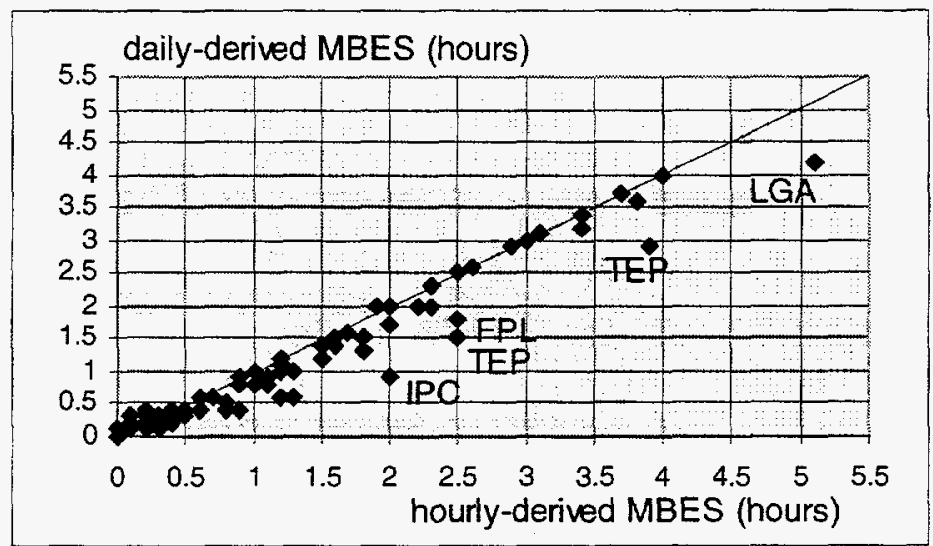

Fig 5: MBES at $10 \%$ penetration derived from daily irradiance and hourly load data, vs. MBES derived from hourly irradiance and hourly load data 


\section{INVESTIGATIONS PRESENTED IN THIS REPORT}

Three new tasks following up on the above are covered in this report.

\section{Expanding the number of Experimental Loads}

This task has two objectives.

1. To increase the experimental data at hand and validate the relationships observed between capacity and load shape.

2. To provide a service for utilities interested in acquiring information about PV effective capacity for their territory or portions thereof (e.g., substations)

\section{Mapping ELCC in the United States}

Applying the effective capacity-load shape relationship mentioned above provides a first estimate of PV's effective capacity for any utility when only knowing simple characteristics of its load, hence bypassing the need for experimental load and solar radiation data. It is thus possible to estimate PV's effective capacity for the great majority of US utilities and use this as a sound input for a mapping exercise.

\section{Investigating localized Loads:}

The objective of this task was to expand the study toward sub-utility loads, in particular building loads. The EPA PV-DSM project provided both the (measured) PV output and load data necessary for this investigation. Several customer loads within the New York Power Authority's (NYPA) service territory were also made available to us. The rationale for this task was:

1. To identify PV load management opportunities as a function of building type and service territory.

2. To include user load and ground-derived data in the development and evaluation of the PV capacity/load shape relationships. 


\section{EXPERIMENTAL DETERMINATION OF EFFECTIVE CAPACITY}

\subsection{Standard Service to Participants}

Any utility or other interested party could, at no cost, take part in the project by providing hourly system or sub-system load data for 1987 and 1988 -- corresponding to our satellite irradiance data set -- or by providing both load data and irradiance data for any other time period. In return, they would receive summary reports consisting of:

1. A qualitative load matching summary comparing summer and winter mean and peak daily load profiles with fixed and 2-axis tracking nominal PV output. An example of this summary is provided in Fig. 6 for the Jersey Central Power and Light Utility.

2. Quantitative load matching graphical and tabular summaries for fixed and tracking PV. These summaries include results for each effective capacity benchmark (see Fig. 7).
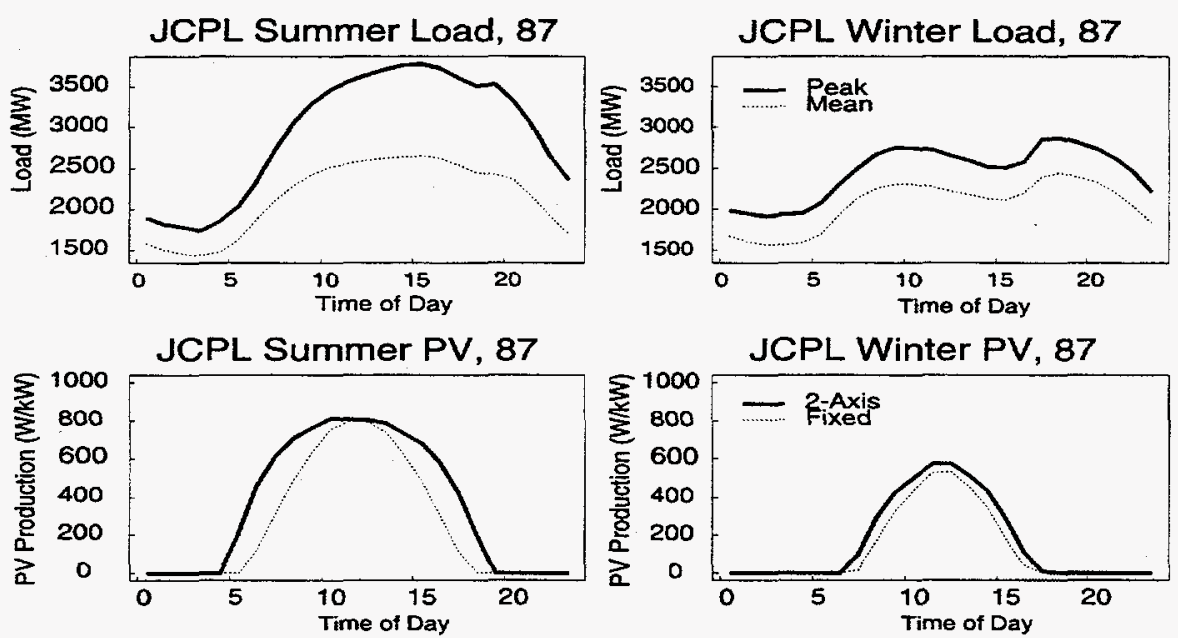

Fig. 6: Example of qualitative load matching summary
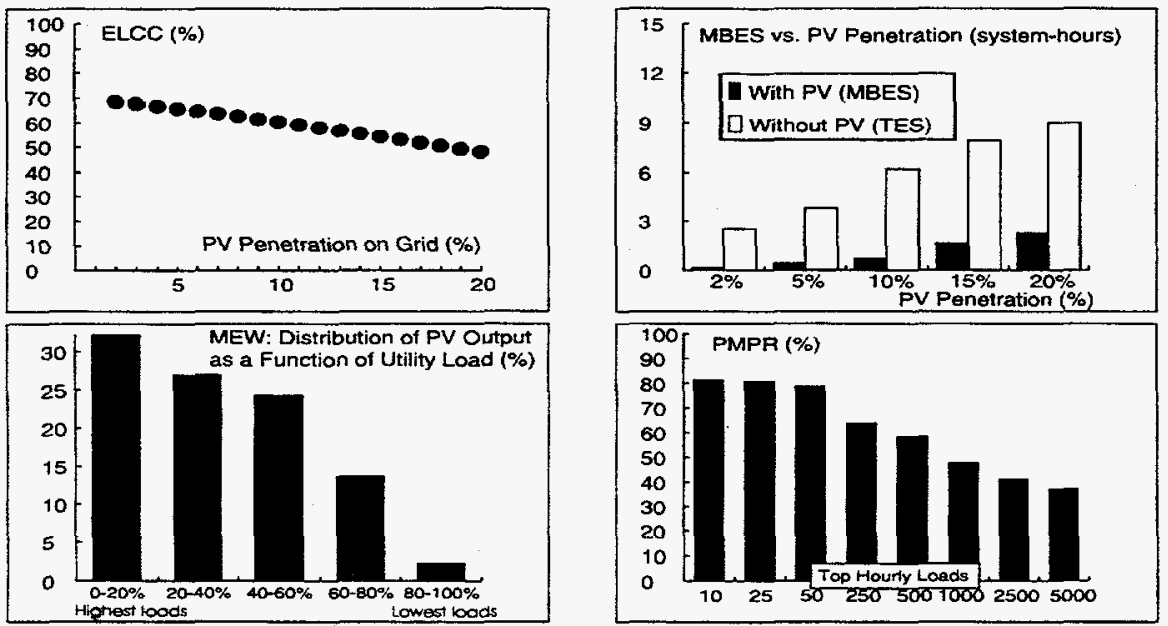

Fig. 7: Example of quantitative load matching summary (JCP\&L, 2-axis-trk. PV) 


\subsection{Current Status on Experimental Loads}

As of this writing, a total of 109 load-years have been analyzed. These include 44 utilities (1-to-3 years each) and 18 subloads listed in Table 1 (subloads discussed in more detail in section 5).

\section{TABLE 1}

\begin{tabular}{|c|c|c|c|c|c|c|c|}
\hline load & & years & irradiance & load & & years & Irradiance \\
\hline type & Load Name & sturlied & data source & type & Load Name & studied & data source \\
\hline utility & Atlantic Electric (NJ) & $87,\{8,94$ & sat \& gind & utility & Northeast Utility Systern (CT) & 87,88 & satellite \\
\hline utility & Central Hudson (NM) & 87,188 & satellite & utitiity & New England Power Pool (MA) & 94 & satellite \\
\hline utility & City of Austin (TX) & 87,38 & satellite & utility & New York Power Authority (NY) & $87,88,94$ & sat \& grnd \\
\hline utility & Connecticun Light and Power (CT) & 87,38 & satellite & utilify & New York State Electric and Gas (NY) & 94 & satelite \\
\hline utility & ConEdison (NY) & 87,38 & satelite & Lutility & Omaha Public Power (NE) & 87,88 & satellite \\
\hline utility & Carolina Power and Light (NC) & 87,38 & satellite & utility & Pacitic Gas and Electric (CA) & 87,88 & satellite \\
\hline utitity & Colorado Public Service (CO) & 87,108 & satellite & utility & Public Senvice Co. of New Hampshire (NH) & 87,88 & satellite \\
\hline utility & Delmarva Power (DE) & 87,138 & satellite & utitility & Portland General (OR) & 93 & sateilite \\
\hline utility & Duke Power (NC) & 87,138 & satellite & utility & Southern California Edison (CA) & 87.88 .94 & sat $\&$ grnd \\
\hline utility & Empire District Electric (MO) & 87,138 & satellite & utillity & Sacramento Municipal Utility District (CA) & 87,88 & satellite \\
\hline utility & Florida Power Corporation (FL) & 87,138 & satellite & untity & Southern Elactric System (AL) & 87.88 & satelite \\
\hline utsity & Florida Power and Light (FL) & 87.188 & satellite & utility & Sierra Pacific Power Company (NV) & 87,88 & satellite \\
\hline utility & Gainsville Regional Utility & 87,138 & satellite & unility & Salt River Project (AZ) & 87.88 & satellite \\
\hline utility & Holyoke Water Power Corp. (MA) & 87,138 & satellite & utility & St. Joseph Power and Light (MO) & 87.88 & satellite \\
\hline utitity & idaho Power Company (ID) & 87,38 & satellite & utilitity & Tucson Electric Power (AZ) & 87,88 & satellite \\
\hline utility & Jersey Central Power and Light $(\mathrm{NJ})$ & 87,138 & satellite & utitity & Texas utilities (TX) & 87,88 & satellite \\
\hline utility & Kansas City Power and Light (MO) & 87,138 & satellite & utility & Utilicorp United (MO) & 87,88 & satellite \\
\hline utility & Long Island Lighting Company ( $\mathrm{NM}$ ) & 87,138 & satellite & utility & Union Eloctric (MO) & 87,88 & saselinte \\
\hline utitity & Lincoin Electric service (NE) & 87,138 & satellite & utility & Wisconsin Public Service (WI) & $87,88,94$ & sat \& grnd \\
\hline utity & Metropolitan Edison $\langle\mathrm{PA}\rangle$ & 87,38 & satellite & utility & Western Mass. Electric (MA) & 87,88 & satellite \\
\hline utility & New England Electric Power Corp. (MA) & 87,38 & satellite & sub-sin & Kerman Substation (CA) & 91.92 & satellite \\
\hline utility & Niagara Mohawk (NY) & 87,38 & satellite & customer & 8 NYPA Customers & 93 & ground \\
\hline utitity & Nevada Power (NV) & 87,38 & satellite & customer & 9 EPA Building loads & 94 & ground \\
\hline utility & Northern States Power (MN) & $87,38,94$ & sat \& grnd & & & & \\
\hline & & & & & & & \\
\hline
\end{tabular}

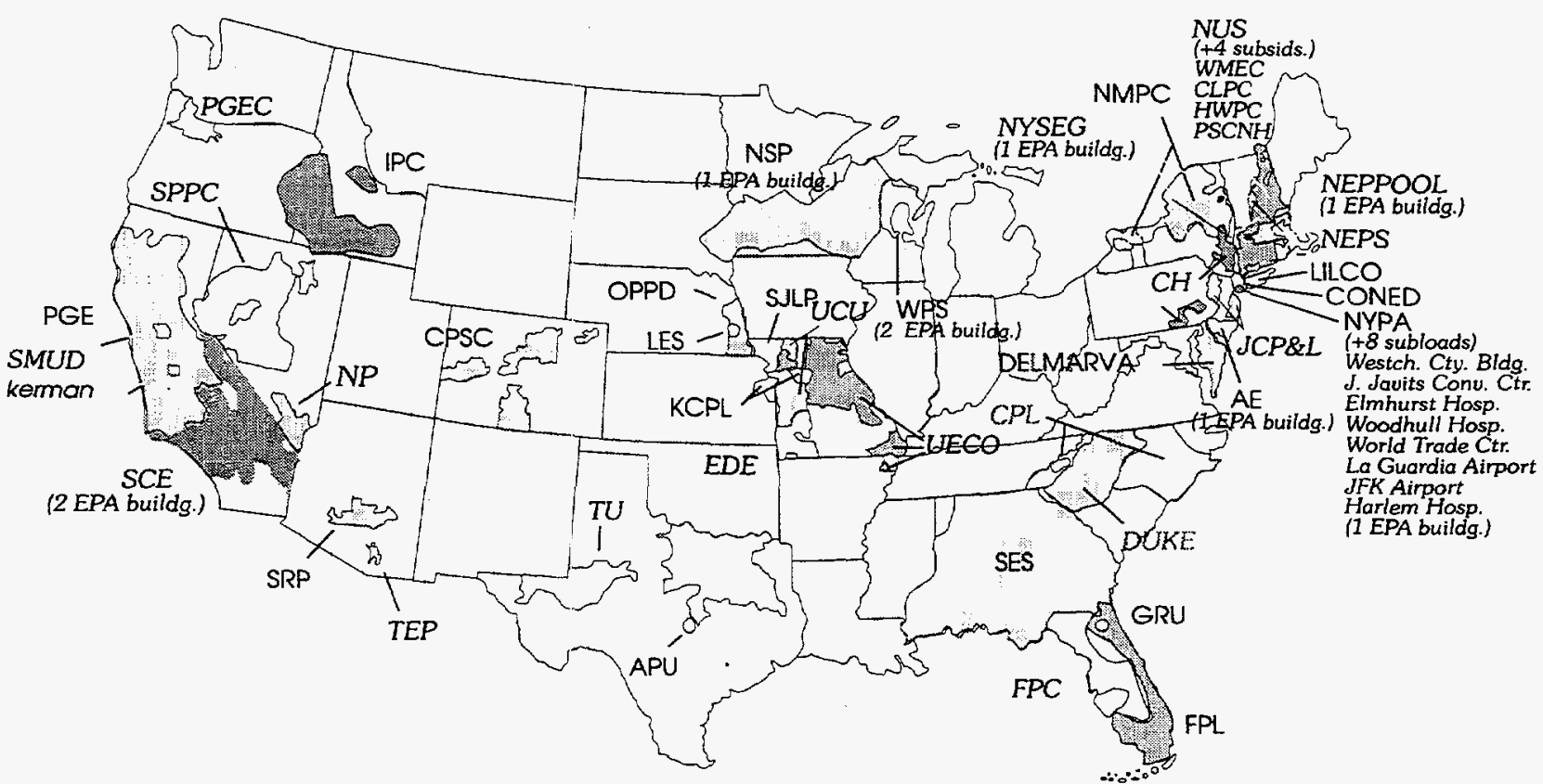

Fig 8: Utilities and "sub"-utilities investigated in this report 
The load sample is diverse in terms of geographical distribution, and size. Most climatic and socio-economic US regions are adequately covered (Fig. 8) with service territories ranging from a few square miles (less for subloads) to over 100,000 square miles. Sizewise, loads span over 6 orders of magnitude from a few kW to over $20 \mathrm{GW}$ (Fig. 9).

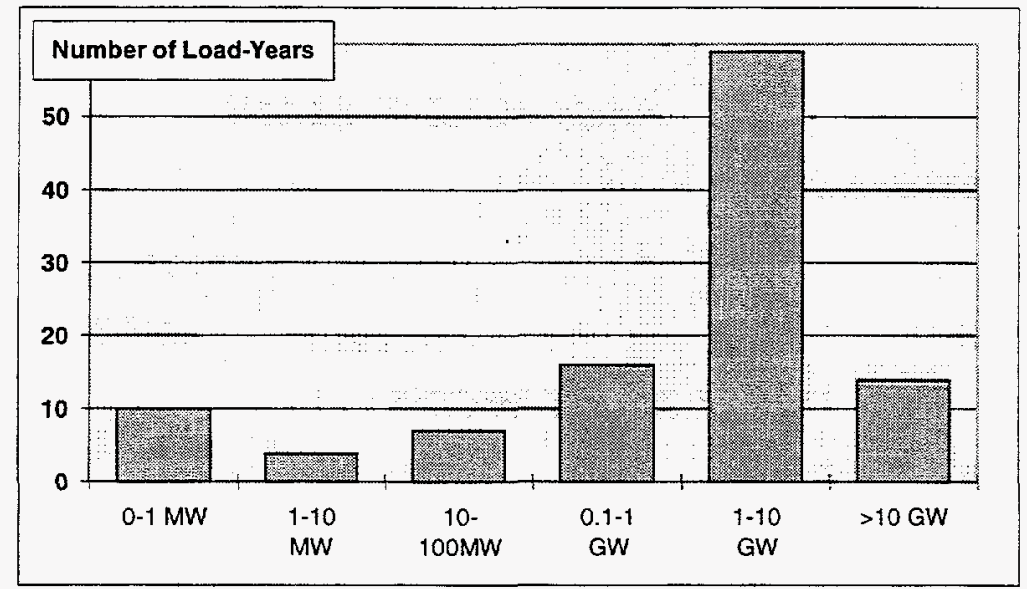

Fig 9: Size distribution of investigated loads

\subsection{Overview of Effective Capacity Determination Results}

We present a brief overview of results obtained for the set of 109-load years using each of the benchmark parameters.

Figure 10 illustrates ELCCs (at 2\% load penetration) derived for each load for fixed and 2 -axis trk. systems. In this figure, as well as in the other figures below, data are sorted by increasing 2 -axis trk. ELCC. As we had remarked before, tracking ELCC at modest $2 \%$ penetration level is substantial for the majority of loads studied, considerably above the resource's capacity factor. Fixed PV ELCCs are on the average $12 \%$ smaller.

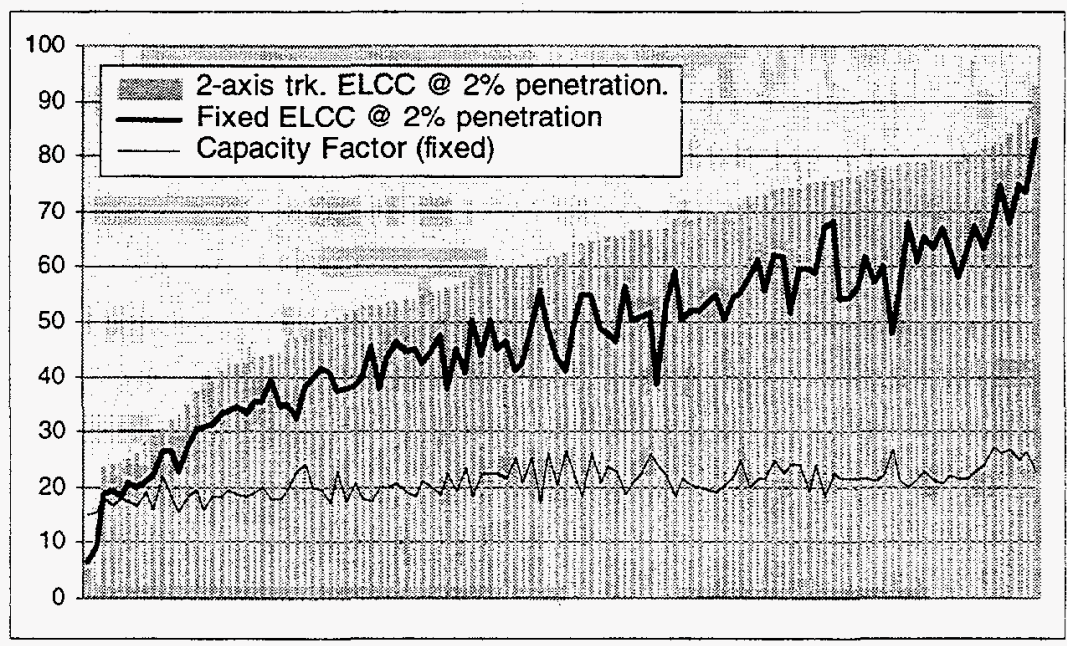

Fig 10: Comparing fixed and 2-axis tracking ELCC with PV capacity factor for 109 loads. Data are sorted as a function of increasing 2-axis tracking ELCC For loads with peaks centered toward the end of the day (e.g., Atlantic Electric, Salt River 
Project, SMUD) the difference between the two configurations is larger, reaching almost $30 \%$ in the case of SMUD. For other loads well centered on the " $9-5$ " business cycle (i.e., " $8-4$ " in terms of solar time) the difference between the two configurations is minimal -this is the case for ConEdison and some of the large New York City Office buildings analyzed .

The effect of PV penetration may be assessed in Fig. 11 where we have plotted 2-axis tracking ELCC at $2 \%$ and $20 \%$ penetration.

Understandably, increasing penetration tends to reduce the effective capacity of $P V$ as non-peak loads must be also met by the PV resource.

Figure 12 provides an

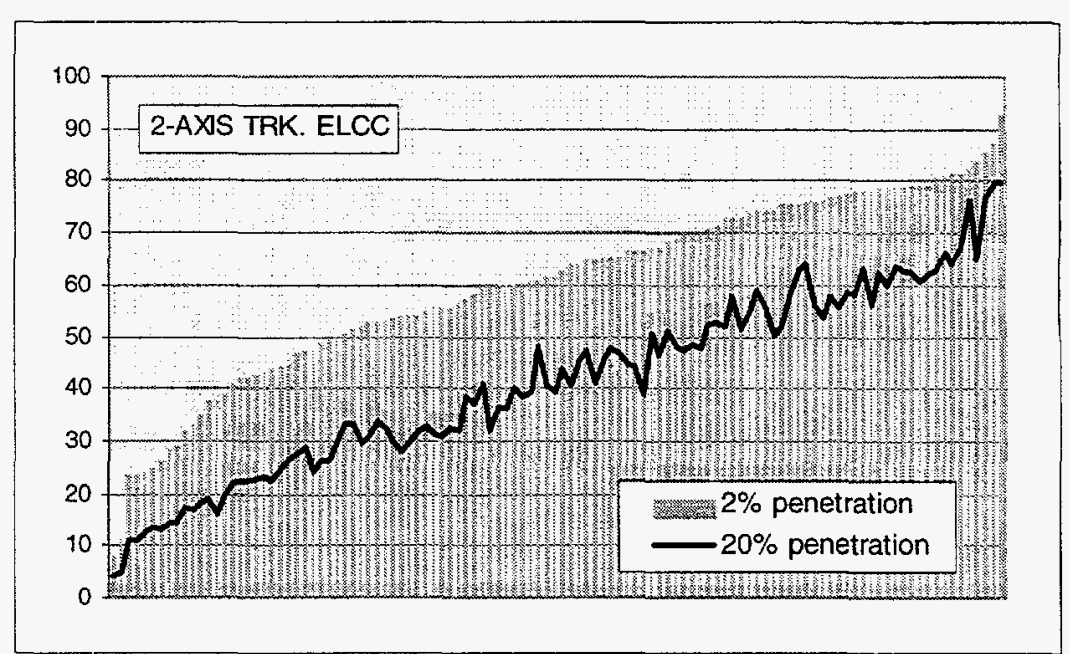

Fig 11: Comparing ELCC at low and high penetration for 109 loads overview of PV's effective capacity as measured by the MBES benchmark. This overview is provided for a $10 \%$ penetration ( $90 \%$ threshold) level. The parameter TES (storage energy required, without PV, to meet all loads above the $90 \%$ threshold) averages about 6 systemhours for most loads studied -- e.g., for a peak load of $1 \mathrm{MW}$ and a $90 \%$ threshold, this would amount to $600 \mathrm{kWh}$. With $\mathrm{PV}$, the storage requirements may be considerably reduced when ELCC increases, with less than 1 hour needed for over half of the loads studied -- for fixed PV the requirements are higher, but still

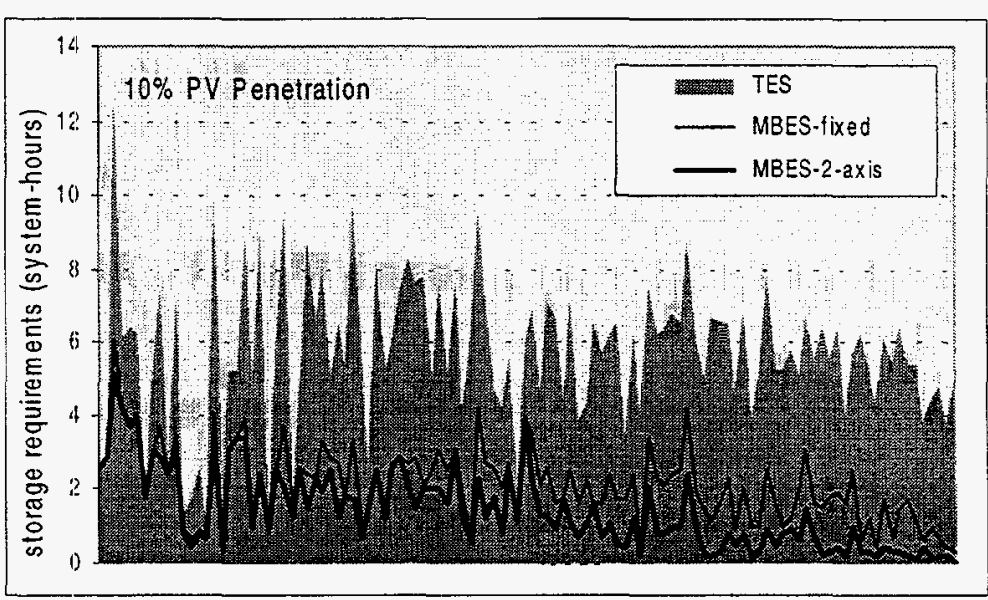

Fig. 12: Comparing Minimum Buffer Storage Requirements with and without PV considerably less than the TES requirements.

We compare the ELCC and the PMPR (50 highest loads) parameters in Fig. 13. The trend is similar. However, the PMPR tends to be higher and more bimodal. Because it represents an average, the PMPR is considerably less discriminating than the LOLP-based ELCC. The same may be said of the MEW parameter. In Fig. 14, we compare the 
fraction of PV output coincident with the $20 \%$ highest loads of each utility with the ELCC parameter. The MEW's dynamic range, hence its ability to delineate effective capacity, is considerably smaller than that of the ELCC.

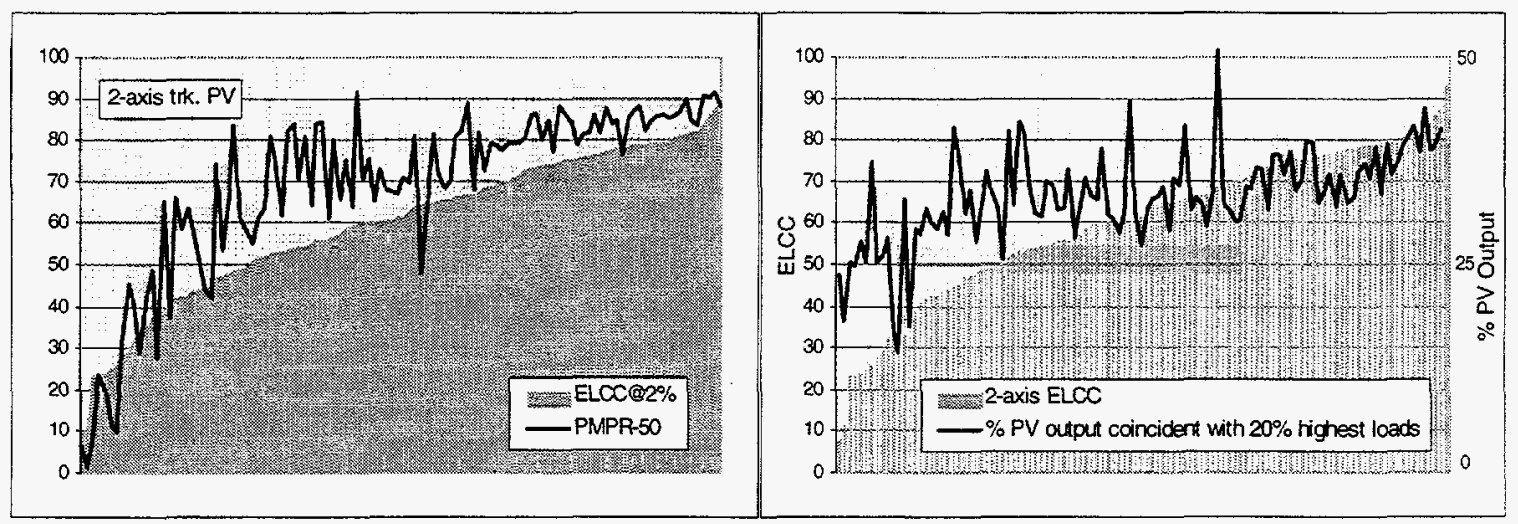

Fig 13: Comparing ELCC and PMPR benchmarks

Fig 14: Comparing ELCC and MEW benchmarks

\subsection{Impact of Solar Resource and Load Characteristics on Effective Capacity.}

The relationship between the "traditional" solar resource (average global irradiance) and effective capacity (as quantified by 2 -axis/2\% ELCC) is illustrated in Fig. 15. This relationship is weak, fully confirming our earlier observations that high capacities may be found in low insolation regions.

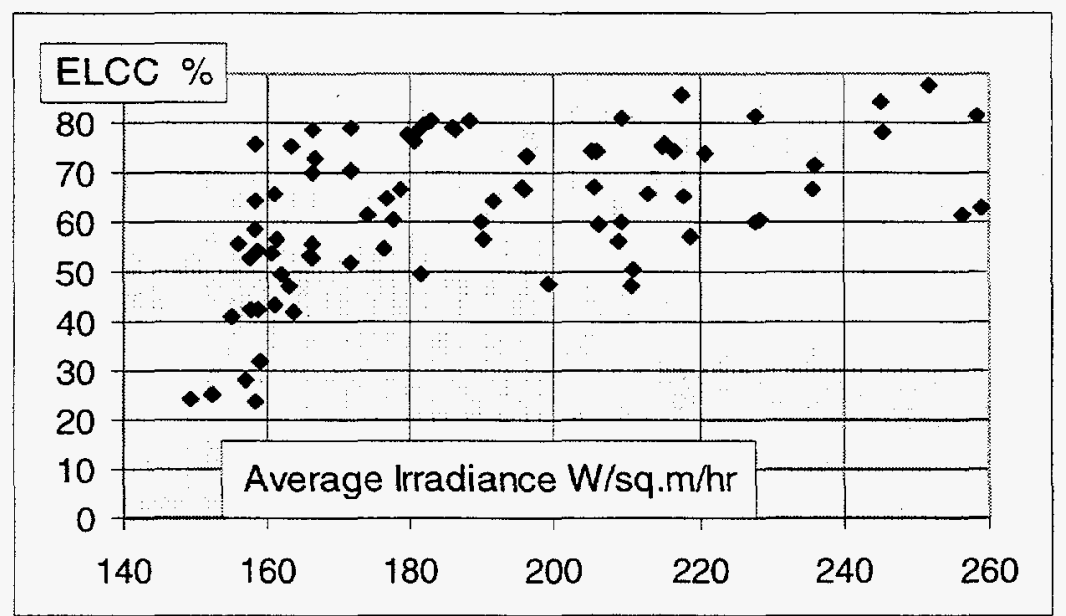

Fig. 15: Effective capacity as a function local solar resource

On the other hand, when plotted against a parameter based strictly on load shape characteristics, the ELCC exhibits a strong relationship, as seen in Fig. 16. This figure includes all utility loads and subloads greater than $500 \mathrm{KW}$ (a total of 101 load-year data points) -- the case of smaller loads is discussed in section 5 . The load shape parameter is 
the modified summer to winter peak load ratio (mswpr). The original swpr was modified in order to account for other characteristics which have secondary impact on the effective capacity. These include: the time of the summer peak, tp the time of the summer peak shoulder (defined as peak -10\%), $t p^{\prime}$, the magnitude of the summer peak load, $s p$, the summer peak load excursion (difference between, highest and lowest peak day load), exr, the summer to off-season peak load ratio, sopr, the time of the winter peak load, $t p w$, and the time of the evening peak shoulder, tpw'. The current, still preliminary, expression for the modified peak load ratio is provided in Table 2 .

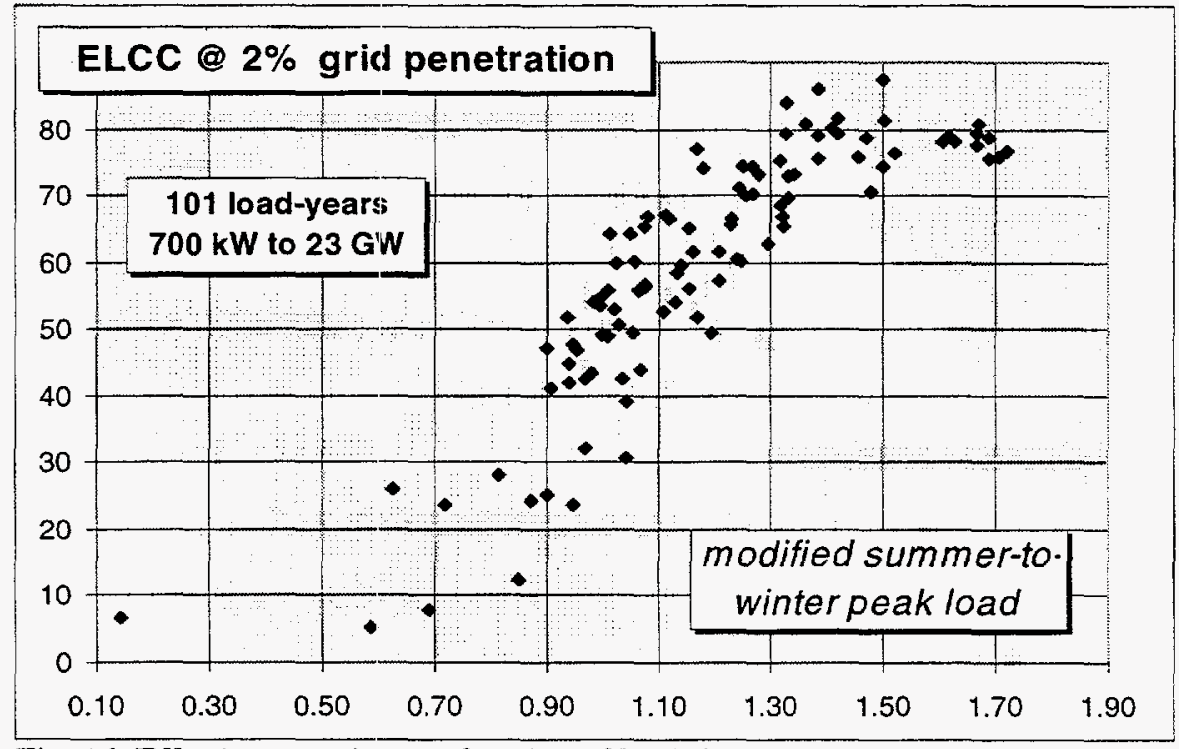

Fig. 16: Effective capacity as a function of load shape

TABLE 2

MODIFIED SUMMER-TO-WNITER PEAK LOAD RATIO

swpr * $\left(\left\{1-M I N\left(4, M A X(0, t p-17)+M A X(0,10-t p)^{\star} 0.05\right\}\right.\right.$ * $\{1-M I N(5, M A X(0, t p '-20.5)) / 50\}$ *

$\left\{1-M A X\left(0,0.3^{*}\right.\right.$ exr $\left.\left.) / 2\right\}\right\}^{*}\left\{\right.$ MAX $\left(0.25,1-\left(\right.\right.$ MAX $(0, \text { swpr/sopr-1-0.2) })^{\star}(1-M I N(1, M A X(0,($ sopr -0.7$\left.\left.) / 0.4)))\right)\right\}$ * $\left\{1+M A X\left(0.3-1 F\left(\left(t p w^{\prime}-t p w\right)>0,\left(t p w w^{\prime}-t p w\right), 24-\left(t p w-t p w^{\prime}\right)\right)\right)^{*} 0.05\right\}^{*}$

$\{\mid \mathrm{F}(\mathrm{sp} \mid>100,1, \mathrm{IF}(\mathrm{sp} />25,0.95, \mathrm{IF}($ spl $\mid>7,5,0.9, \mathrm{IF}(\mathrm{spl} />2,0.85,0.8))))\})$

\subsection{Parameterizing the impact of PV configuration and PV penetration on effective capacity benchmarks}

The mswpr-effective capacity relationship presented above is defined for 2-axis trk. ELCC at $2 \%$ penetration. As shown in the mapping task below, this relationship constitutes a very productive tool. In an attempt to extend this usefulness to other PV configurations, other penetration levels or other benchmark parameters, we observed whether systematic relationships between these benchmarks could be observed. 
The influence of penetration may be seen in Figs. $17 \mathrm{a}, \mathrm{b}$ and $\mathrm{c}$, where experimentally derived ELCC at 5\%, 10\% and 20\% have been plotted against the 2\% benchmark. The relationships are not linear, but strongly deterministic and simply modelable. That is, if ELCC at $2 \%$ is known, then ELCC at other penetration levels may be estimated with adequate precision.

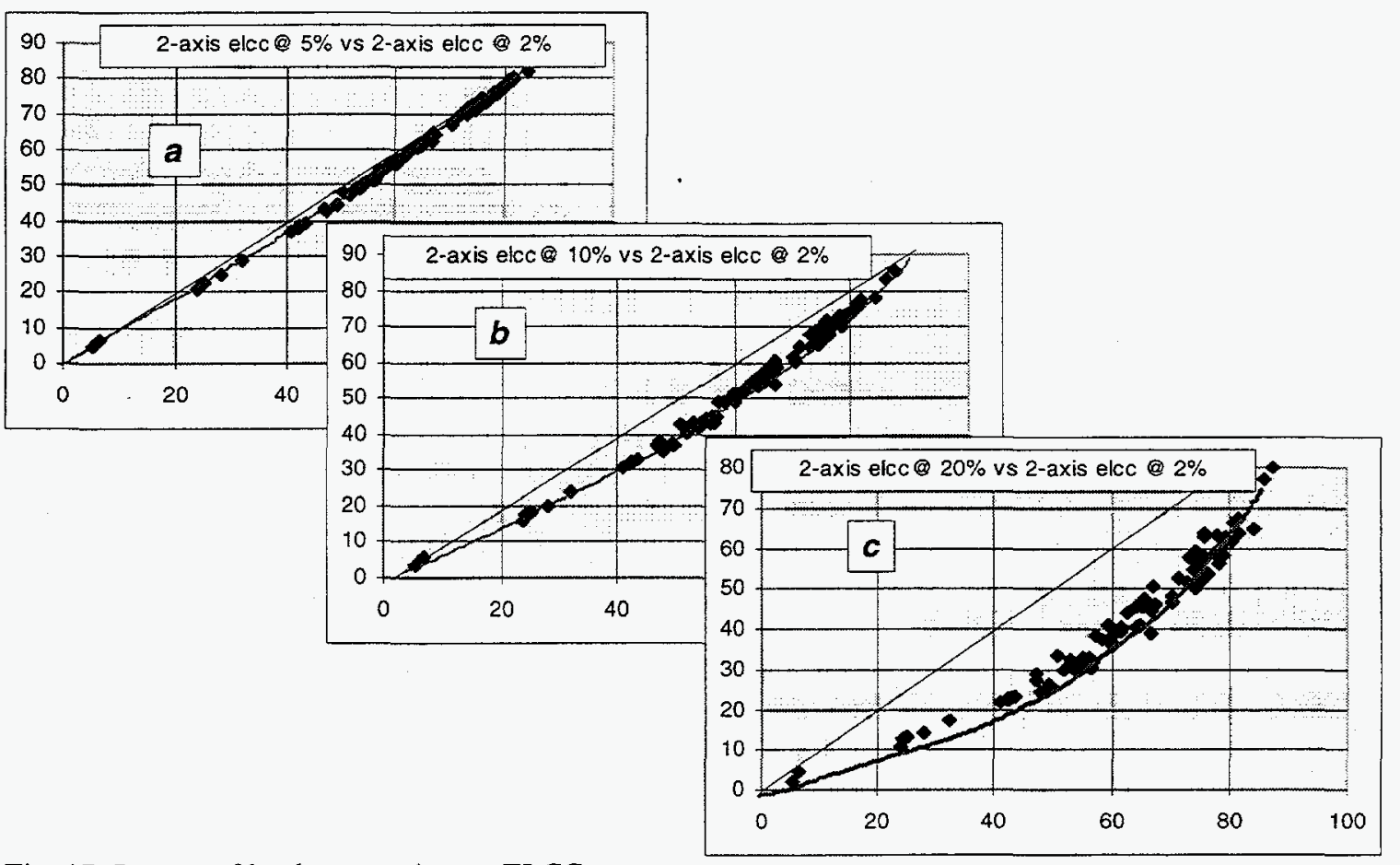

Fig. 17: Impact of load penetration on ELCC

The impact of array configuration requires more input to be fully accounted for. In Fig. 18, we have plotted fixed ELCC at $2 \%$ penetration against 2-axis tracking ELCC at $2 \%$. There is some scatter as noted above in Fig. 10. However, if one accounts for time and width of summer peak, it is possible to get a very tight fit between fixed ELCC measured directly, and modeled from 2-axis trk. ELCC (see Fig. 19).

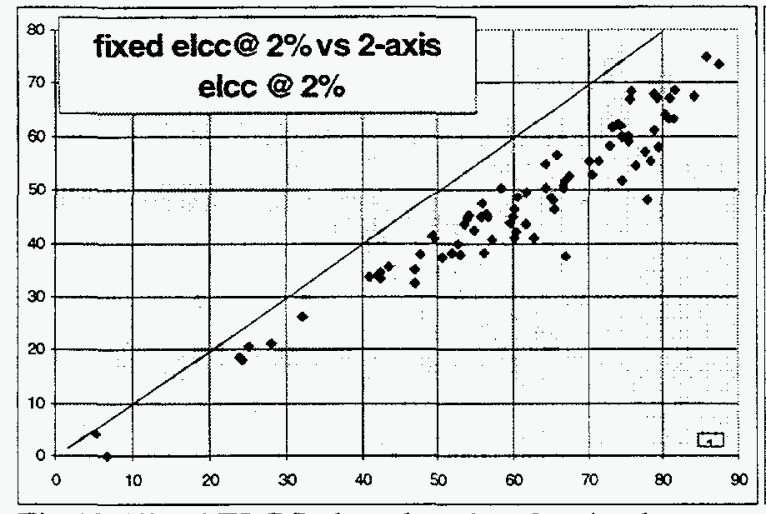

Fig 18: Fixed ELCC plotted against 2-axis trk. ELCC

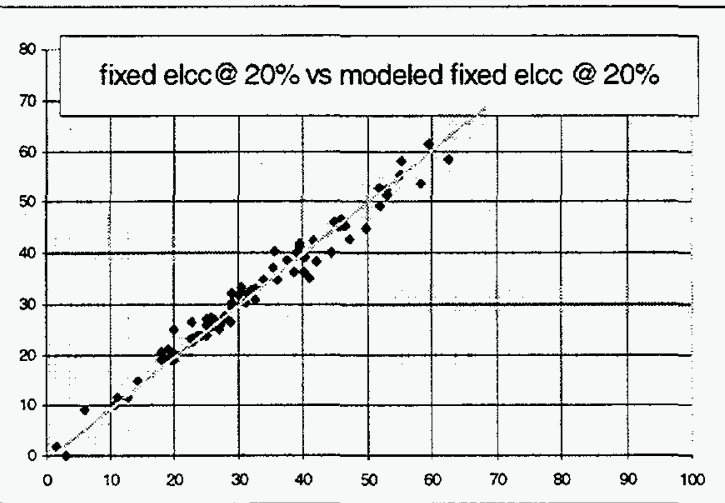

Fig 19: Fixed ELCC modeled from 2-axis ELCC plotted against actual fixed ELCC 
The relationship between 2\%-ELCC and the 20\%-MBES is illustrated in Fig. 20. There is noticeable scatter between the two, reflecting the different nature of the two benchmarks. The relationship is nevertheless remarkably tight for points with higher effective capacities.

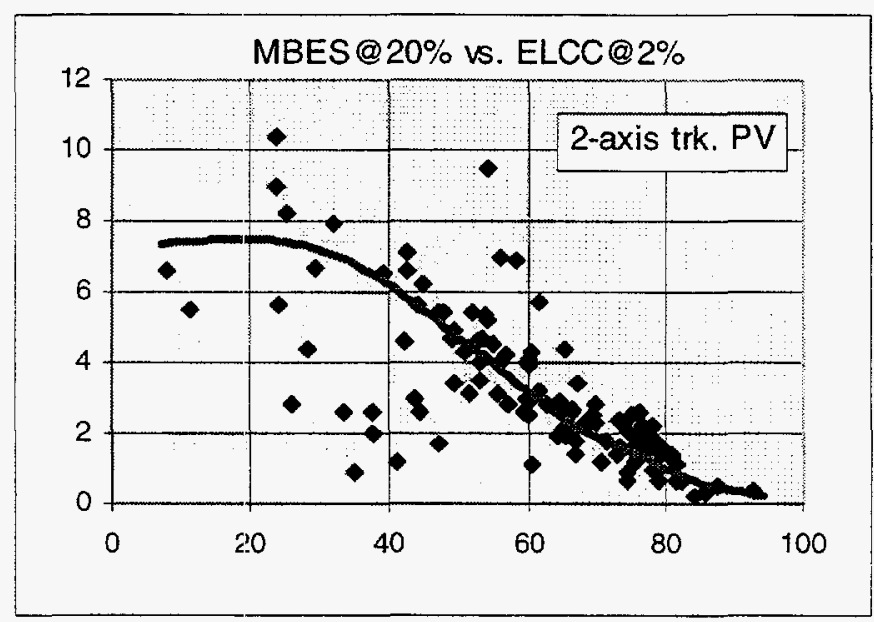

Fig 20: MBES (system hours) vs. ELCC (\%) 


\section{MAPPING PV'S EFFECTIVE CAPACITY IN THE US}

\subsection{Methods}

The mapping process is described in detail in the article 'Geographical Distribution of PV Effective Capacity in the United States' provided in Attachment No. 1. This is briefly summarized here.

As mentioned above the relationship between load and effective capacity constitutes a powerful investigative tool. Indeed, knowing a few facts about the load is sufficient to obtain an adequate estimate of effective capacity. Simple load characteristic parameters are considerably easier to obtain and to process than hourly insolation and load time series.

We acquired summer and winter peak load information for 1993 for 500 utilities with 75 MW or more of installed capacity, i.e., all but a few major US utilities. Using a simplified version of the relationship shown in Fig. 16, we were able to estimate the ELCC for almost every utility in the US.

A considerable amount of time and effort was spent, outside of this project, to grid utility service territories on a $2^{\circ}$ latitude-longitude mesh. The ELCC for each grid cell was determined by a weighted average of utilities (or portion thereof) within each cell. The $2^{\circ}$ map was then fed to a standard mapping program where isopleths were overlaid.

The resulting ELCC map [15] is shown in Fig. 21. Its features are counter-intuitive and considerably different from the "traditional" solar energy map of the US shown in Fig. 22.

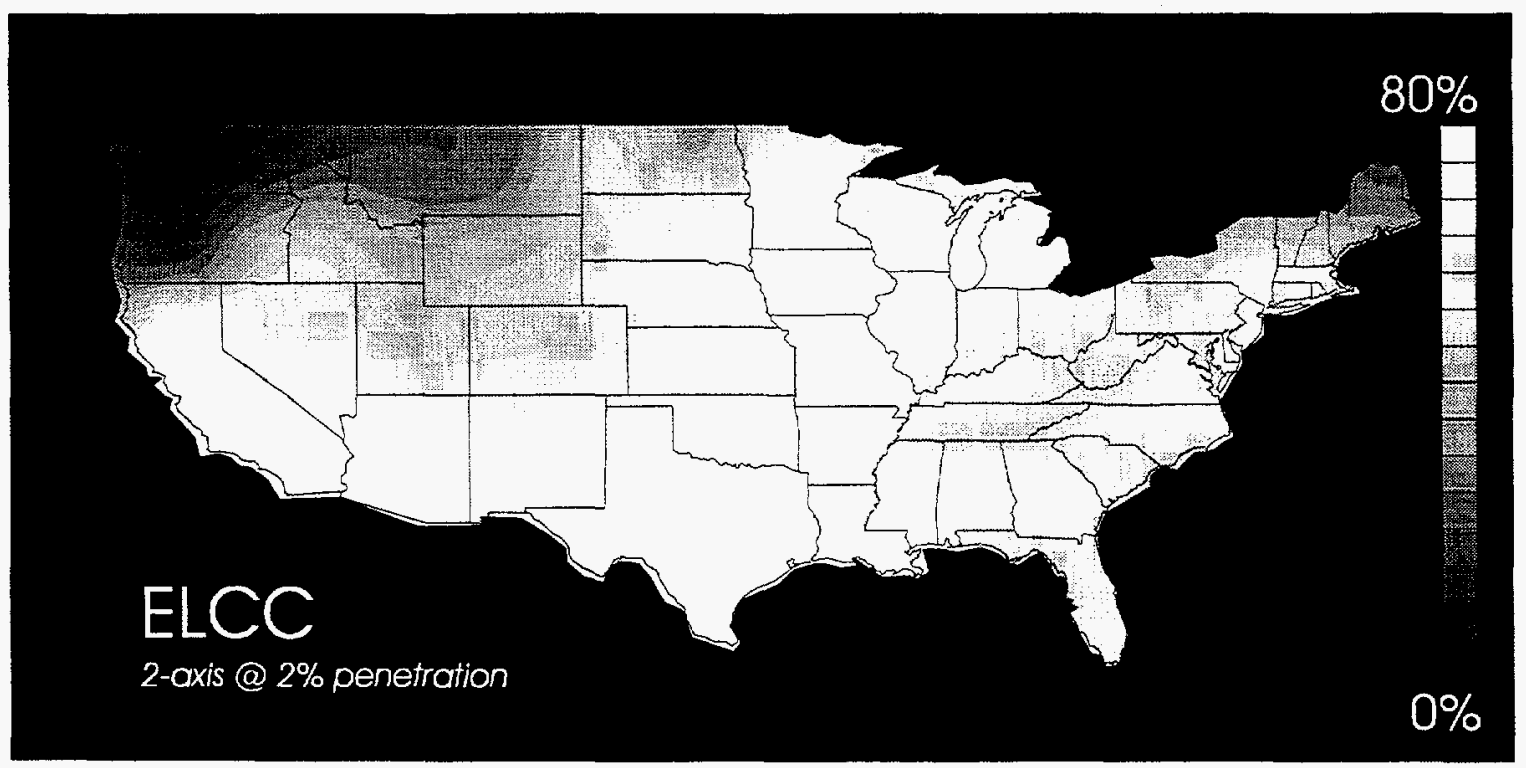

Fig 21: Distribution of ELCC in the United States (2-axis tracking systems, 2\% penetration) 


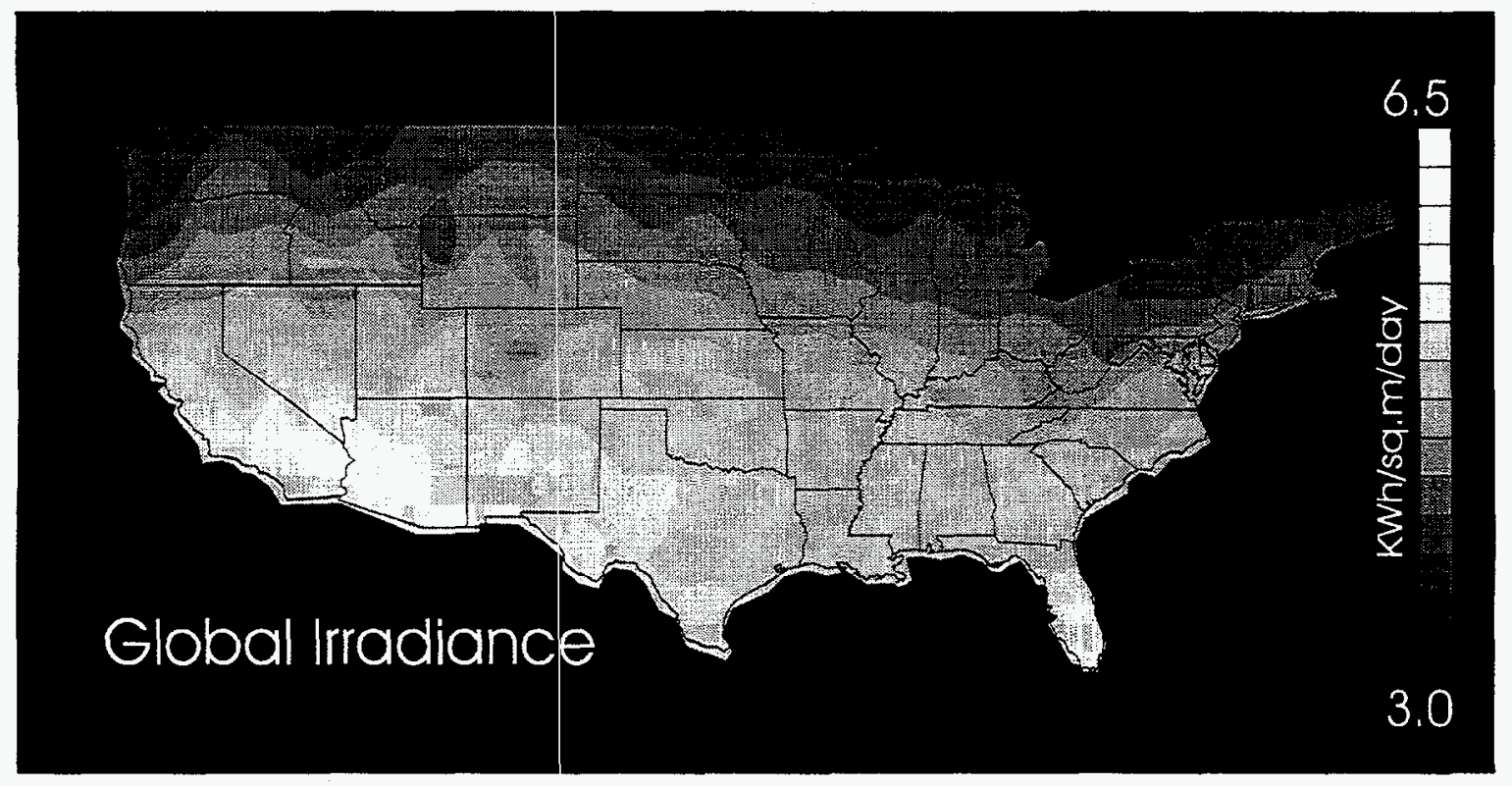

Fig 22: Distribution of Global Irradiance in the United States

There are three regions of high effective capacity:

- The largest region covers the central US from the northwestern Great Plains and the metropolitan areas of Chicag口 and Detroit down to the lower Mississippi Valley and, to a lesser extent Texas. The core of this region features the highest capacities observed in the United States.

- The second region includes California, western Arizona, and southern Nevada.

- The third region, the smallest geographically, but very large in terms of installed utility capacity, spans the eastern metropolitan area extending from North Carolina to Boston.

The features of this map are fully consistent with the experimental evidence gathered from our sample utilities shown in Fig. 8. This is remarkable given the fact that the gridded map was derived solely from load shape data, without solar resource input.

The largest discrepancies between the "traditional" solar energy map and the effective capacity map are found throughout much of the western US and the extreme southeastern US, two traditional solar regions, and in the northern heartland and the eastern seaboard which have not been considered to be regions of high solar potential.

The effective capacity map does reflect key climatic and socio-economic realities, the combination of which is highly relevant to the effective capacity of PV. The regions of high effective capacity tend to match areas associated with strong summer heat waves (particularly in the case of the central US region). These regions may also be associated with areas where utility demand is driven by commercial air conditioning (particularly in the case of the eastern and western metropolitan regions), and where the electrical heating 
load is not significant (i.e., absence of cold weather conditions and/or use of other heating energy sources such as oil or gas).

\subsection{Applicability of the Results}

As we sketched in Fig. 23, the value of PV depends on (1) the amount of energy produced and the value of energy, (2) the effective capacity of the system and the value of capacity and (3) the cost of the system and the financing/fiscal environment. The new map fills one of the missing pieces of information necessary for a comprehensive assessment of PV economic opportunities in the US

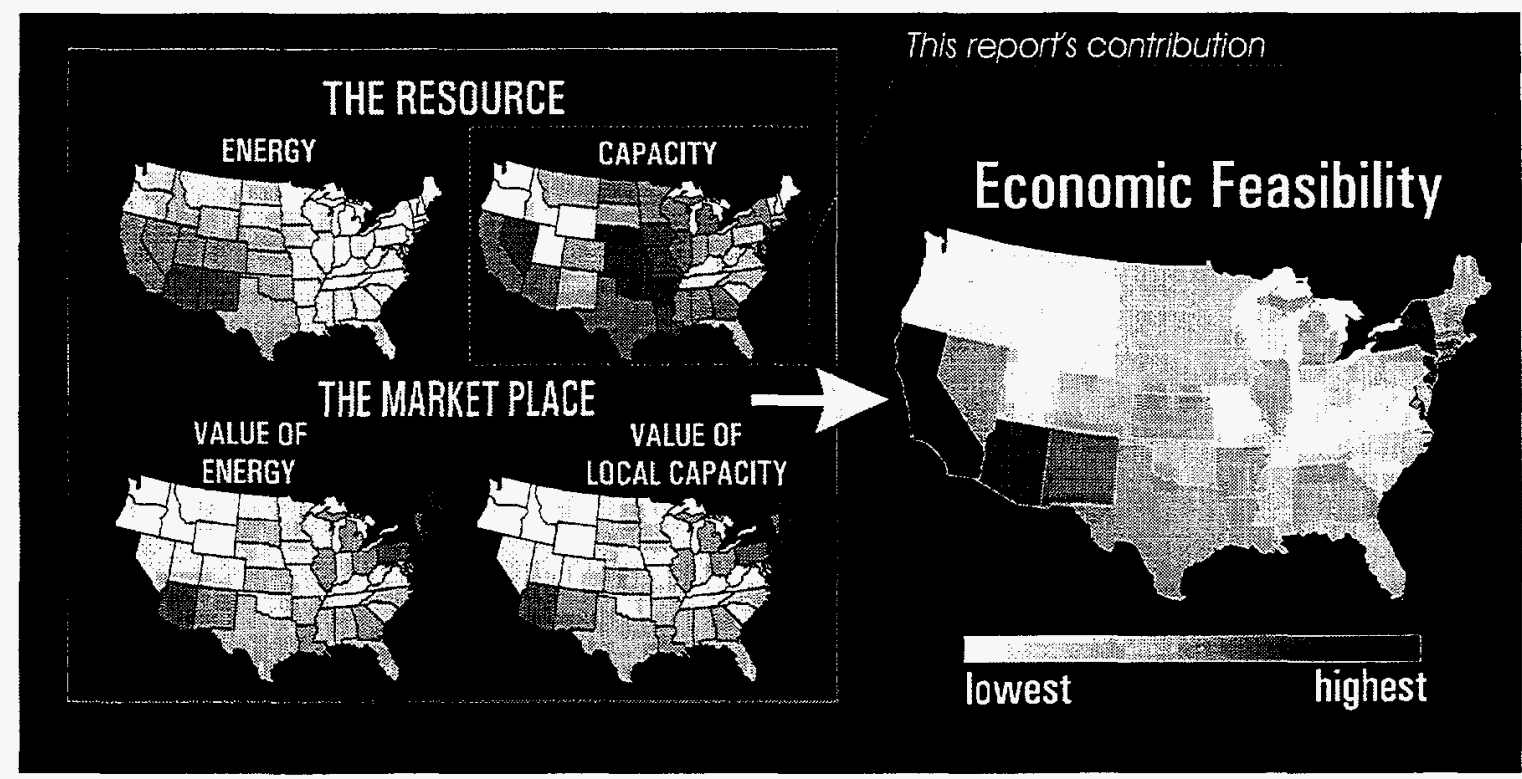

Fig 23: Illustration of this report's contribution to the evaluation of PV economic feasibility

\subsection{Follow-on Mapping Tasks}

The work presented above should be extended on three fronts.

1. Evaluation of year-to-year variability and long term trends: The map is based only on 1993 data and could well reflect unusual (climatic or other) circumstances in some areas of the country. It is doubtful, however, that its overall structure should be questioned, given its consistency with the partial experimental evidence from 1987 and 1988. Nevertheless, it would be important (and relatively straightforward) to repeat the exercise over several years in order to: (1) eliminate the risk of unusual circumstances, (2) observe year-to-year variability, and (3) identify possible trends toward (or away from) increased PV's effective capacity.

2. Extension to monthly effective capacities: In many instances, economic evaluation requires a monthly or at least seasonal input, because rates and their driving economic 
factors may vary considerably throughout the year [16]. As a follow-on task, we will attempt to extrapolate monthly effective capacity maps from the yearly map, using our $100+$ load-year experimental data set as a template.

3. Increasing geographical resolution: It must be stressed that the resolution of the present map is still very coarse and does not reflect localized opportunities. A recent study by Bryan and Perez [17] shows that opportunities are bound to exist even in areas of the country with marginal effective capacities. This study is provided in Attachment 2. There is no reason why the methodology applied here at the national level be could not be applied at the regional (e.g., State) level. 


\section{FOCUS ON CUSTOMER LOADS}

Eighteen of the experimental 109 load-years available to us are customer or substation loads. These loads are described in Table 3.

TABLE 3

\begin{tabular}{|c|c|c|c|c|c|c|}
\hline & Load & load size & Data & Service & years & irradiance \\
\hline Load Name & type & $\mathrm{kW}$ & Source & Territory & studied & data source \\
\hline Kerman Substation (Kerman, CA) & Substation & 10,627 & PG\&E & PG\&E & 91,92 & ground \\
\hline Elmhurst Hospital (NY City) & Hospital & 795 & NYPA & NYPA & 93 & ground \\
\hline Harlem Hospital (NY City) & Hospital & 3,128 & NYPA & NYPA & 93 & ground \\
\hline Jacob Javits Convention Center (NY City) & Offices/Convention & 14,960 & NYPA & NYPA & 93 & ground \\
\hline JFK Airport (NY City) & Airport & 56,900 & NYPA & NYPA & 93 & ground \\
\hline La Guardia Airport (NY City) & Airport & 9,320 & NYPA & NYPA & 93 & ground \\
\hline Westchester County Building (White Plains, NY) & Offices & 1,265 & NYPA & NYPA & 93 & ground \\
\hline Woodhull Hospital (NY City) & Hospital & 5,128 & NYPA & NYPA & 93 & ground \\
\hline World trade Center (NY City) & Office & 73,024 & NYPA & NYPA & 93 & ground \\
\hline NYSEG Service Center (Plattsburgh, NY) & Office & 645 & ATI-EPA & NYSEG & 94 & ground \\
\hline Minnetonka (MN) & Office & 38 & ATI-EPA & NSP & 94 & ground \\
\hline Edwards Airfoce Base (CA) & Residence & 7 & ATI-EPA & SCal-Ed & 94 & ground \\
\hline Palm Desert (CA) & Offices & 94 & ATI-EPA & SCal-Ed & 94 & ground \\
\hline Northeast Utilities Service Ctr. (Berlin, CT) & Office & 877 & ATI-EPA & $\mathrm{NU}$ & 94 & ground \\
\hline Atlantic Electric Headquarters (Pleasantville, $\mathrm{NJ}$ ) & Office & 409 & ATII-EPA & $A E$ & 94 & ground \\
\hline White Plains Middle School (White Plains, NY) & School & 633 & ATI-EPA & NYPA & 94 & ground \\
\hline WPS Service Center, (Ashwobegon, WI) & Office & 287 & ATI-EPA: & WPS & 94 & ground \\
\hline Denmark (WI) & Residence & 15 & ATI-EPA & WPS & 94 & ground \\
\hline
\end{tabular}

\subsection{Validation of load shape - effective capacity relationships for small loads}

As shown in Fig. 16, all customer and substation loads greater than $600 \mathrm{~kW}$ follow the same relationship as larger utility loads. However, as loads get smaller, one observes noticeable departures from the trend (see Fig. 24). We suspect that one the reason for this departure is "load noise": Small individual loads tend to fluctuate independently from the underlying load drivers that are at the basis of Fig. 16's the relationship.

Another reason for trend departure is some degree of "winter load match" found in the case of electrically heated buildings. Indeed, coldest weather in northern regions is often characterized by very clear conditions following cold front passage -- The issue of winter load match would merit further scrutiny at some point, especially with respect to passive solar implications.

The largest departures from the trend are briefly discussed below:

Edwards AFB Residence: This is the largest departure from the trend. It is also the smallest load $(7 \mathrm{~kW})$. In addition, the load has a very narrow peak almost everyday around noontime. In this sunny climate the probability of meeting this peak was very high (although by no means certain), hence the experimentally derived $92 \%$ ELCC. 
The NYSEG building in Plattsburgh: Departure from the trend is not as large as above, however the load matching is substantially higher than would be expected from this strongly winter peaking load $(600 \mathrm{~kW})$. Size in this case does not appear to be the main cause of departure, but rather the fact that the building is electrically heated and may have experienced some degree of "winter load match".

Small Office Building in Minnetonka (MN): Effective capacity for this load, although sizable, is not as high as the main trend would suggest for this highly summer peaking office building. We suspect that size in this case $(38 \mathrm{~kW})$ is the main reason for departure.

White Plains School (NY): Departure from the trend is small but still noticeable. Effective capacity is found to be higher than the trend would suggest for this winter peaking building. The main reason for this may be load noise: the building had a very strong narrow peak in winter. This peak was substantially higher than any other day, and happened to be on a sunny day, hence the relatively high observed ELCC.

Denmark Residence (WI): Here again, departure is not very large, but still noticeable. We surmise that both size $(15 \mathrm{~kW})$ and winter load matching are the cause for trend departure.

All other building and subloads analyzed, ranging in size from less than $100 \mathrm{~kW}$ to over $70 \mathrm{MW}$ did follow the main trend.

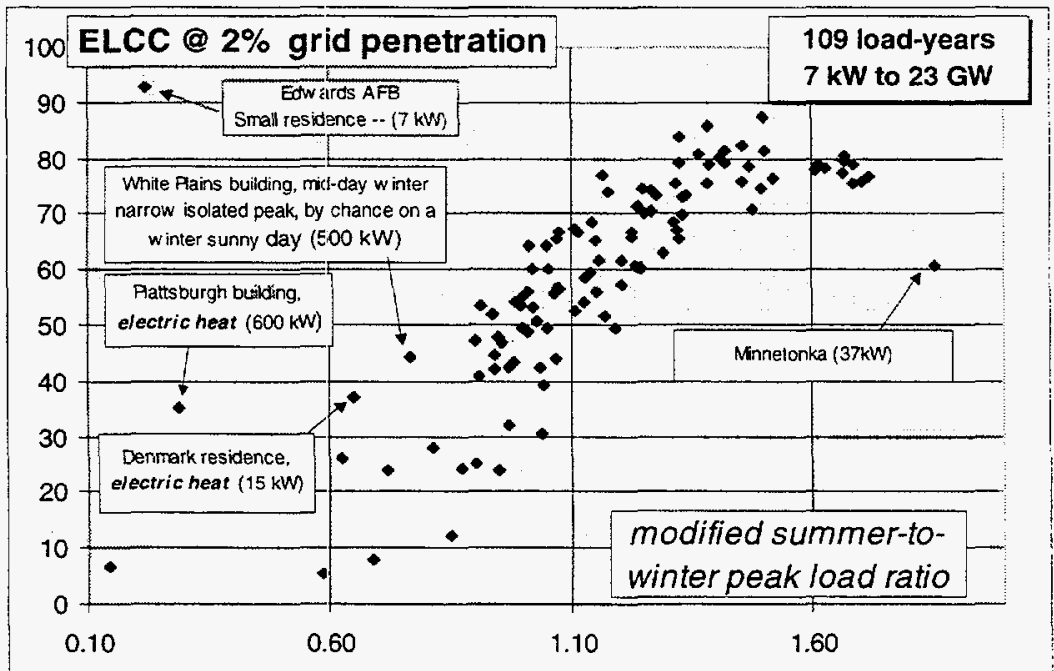

Fig. 24: Departure frorn the ELCC-load shape trend for small and/or electric heat driven loads 


\subsection{Effective Capacity vs. Building Type}

A secondary objective of this task was to attempt identifying PV load management opportunities as a function of building type and service territory. Although the amount of experimental evidence is not nearly large enough to provide definitive results, fragmentary evidence of building type trends do seem to emerge. We stress that these results are very fragmentary and preliminary

In Table 4, we report the average and standard deviation of two load matching benchmarks ( 2 axis tracking ELCC at $2 \%$ penetration and MBES at $10 \%$ penetration) for four building categories where we had at least 2 data points.

TABLE 4

\begin{tabular}{|l|c|c|c|c|}
\hline & $\begin{array}{c}\text { Average } \\
\text { ELCC } \\
(\%)\end{array}$ & $\begin{array}{c}\text { Standard } \\
\text { Deviation } \\
(\%)\end{array}$ & $\begin{array}{c}\text { Average } \\
\text { MBES } \\
\text { (hours) }\end{array}$ & $\begin{array}{c}\text { Standard } \\
\text { Deviation } \\
\text { (hours) }\end{array}$ \\
\hline Hospitals & $63 \%$ & $11 \%$ & 2.3 & 1.2 \\
Offices (no electric heat) & $67 \%$ & $10 \%$ & 0.8 & 0.5 \\
Airports & $33 \%$ & $13 \%$ & 4.3 & 1.2 \\
Residences & $65 \%$ & $39 \%$ & 0.6 & 0.2 \\
\hline
\end{tabular}

Office/commercial air-conditioned, non-electrically heated buildings: These have the highest effective capacity (as measured by the ELCC), averaging $67 \%$. The MBES benchmark shows that less than an hour of storage would be needed in addition to a PV system to guarantee a firm $10 \%$ demand reduction for this type of building.

Hospitals: Effective capacity, as measured by the $2 \%$-ELCC, stands at $63 \%$, showing a good statistical agreement between the resource and the load for very low penetration levels. The MBES at $10 \%$, however, is considerably higher than for office buildings, standing at almost 3 hours indicative of high and lasting offpeak loads for hospitals.

Airports: Both benchmarks indicate only marginal load matching for these mainly $24 \mathrm{hr} . /$ day operations.

Residences: This is an extremely low data sample. The average ELCC is likely meaningless with a $35 \%$ standard deviation. However, it is remarkable that the MBES is very small in both cases. The reason may very well be that because residential loads are typically noisy, it does not take much energy reserve to substantially reduce peak loads. 


\subsection{Follow-on work}

Again, we stress that the results presented in this section are very fragmentary and preliminary, especially with respect to building type relationships. Therefore, follow-on Tasks should focus on acquiring and analyzing a much larger sample of end-use load data.

The data sample could be greatly enlarged by reducing the data request to the load shape parameters described in Table 2, since they appear to be applicable to most buildings (as long as the load is sizable -- above $100 \mathrm{~kW}$-- and is not driven by electric heat) 


\section{CONCLUSIONS}

In this report, we provided solid evidence, based on over 8 million data points, that regional PV's effective capacity is largely unrelated to the region's solar resource. We confirmed however, that effective capacity is strongly related to load shape characteristics. The load shape-effective capacity relationship appears to be valid for enduse loads as small as $100 \mathrm{~kW}$, except possibly, in the case of electrically heated buildings.

This relationship was used as a tool to produce an initial US map of PV's effective capacity. The regions of highest effective capacities include (1) the central US from the northern great plains to the metropolitan areas of Chicago and Detroit down to the lower Mississippi valley, (2) California and western Arizona and (3) the northeastern Metropolitan Corridor. The features of this map are considerably different from the traditional solar resource maps. They tend to reflect the socio-economic and climatic factors that indirectly drive PV's effective capacity: e.g., commercial air-conditioning, little use of electric heat and strong summer heat waves. The map provides a new and significant insight to a comprehensive valuation of the PV resource.

We assembled preliminary evidence showing that end-use load type may be related to PV's effective capacity. Highest effective capacities were found for (non-electrically heated) office buildings, followed by hospitals. Lowest capacities were found for airports and residences. Many more data points are needed, however, to ascertain and characterize these preliminary findings.

Follow on work should focus on:

- Investigating the year-to-year variability and long term trends of effective capacity distribution in the US.

- Investigating the seasonal variability of PV effective capacity distribution in the US.

- Refining the current map geographical resolution (e.g., producing state-level maps).

- Extending the number of end-use customer load (shape) data in order to better characterize possible end-use type / load match relationship. 


\section{ATTACHMENT No. 1}

Geographical Distribution of Photovoltaic Effective Capacity In the United States 


\title{
Geographical Distribution of Photovoltaic Effective Capacity in the United States
}

\author{
Richard Perez and Robert Seals \\ ASRC, The University at Albany, Albany, NY, USA
}

\section{ABSTRACT}

This paper presents a preliminary map of the effective capacity of grid-connected photovoltaic (PV) in the United States. The well defined relationship, recently observed by the authors, between the effective capacity of PV and utility load shapes, was used as a basis for the development of this map. Seasonal peak load data for most large and medium size US utilities for the year 1993 constitute the primary input to this exercise.

\section{BACKGROUND}

\section{Defining PV's Effective Capacity}

PV power plants have traditionally been given low or no capacity credit because their output cannot not be controlled or dispatched. However, many studies have shown [e.g., 1, 2] that, under favorable conditions, particularly when load requirements are driven by commercial air conditioning, PV power is available at peak time, and therefore, can effectively contribute to localized and/or utility-wide generating capacity. Under these conditions, the effective capacity of PV may be considerably higher than its capacity factor. This may have important economic implications, since much of the value of PV (including both its traditional capacity value and its local $T \& D$ value) is linked to its effective capacity.

\section{Quantifying PV's effective capacity}

Several parameters have been introduced to quantify effective capacity. These include both statistical parameters and deterministic parameters [e.g., see 2].

An example of statistical parameter is the Effective Load Carrying Capability or ELCC. This parameter was originally introduced by Garver [3] for non-interconnected utilities. It is defined as the increase in available capacity due to the added resource (in this case, PV) at constant loss of load probability (LOLP). A normalized version of the ELCC (see [2]) is used in this paper. This assumes a generic LOLP for any load studied, making the ELCC solely a function of the relationship between load requirements and PV output. ELCC is reported in \% of installed PV capacity -- in this paper, installed PV capacity is assumed to be summer-peak time AC capacity.

An example of deterministic effective capacity parameter is the Minimum Buffer Energy Storage (MBES) needed, in addition to the PV resource, to guarantee 100\% ELCC (see [2]). This parameter is a measure of the worse case mismatch between the load requirements and the resource. MBES is quantified in terms of installed PV capacity-hours. 
In this paper, we focus our attention on the ELCC parameter as a measure of effective capacity. It should be said however, that, with few exceptions, all load matching parameters tend to agree closely [2].

The ELCC of peak-coincident, but intermittent, resources such as PV has been found to decrease as a function of the penetration of PV on the considered grid. For this study, we consider a moderate level of PV penetration of $2 \%$. In addition, PV's effective capacity is, of course, a function of the considered type of PV array, and at this time, we consider exclusively 2-axis tracking configurations. Therefore, in the remainder of this paper, the terms "effective capacity", "ELCC", and "2-axis tracking ELCC at $2 \%$ penetration" will be used interchangeably.

\section{OBSERVING A RELATIONSHIP BETTWEEN LOAD SHAPE AND ELCC}

It is an increasingly recognized observation that the effective capacity of PV is related to the indirect feed-back between solar irradiance and air conditioning-driven load requirements: high insolation conditions tend to enhance hot weather conditions which drive up day-time air conditioning demand.

However, because so many parameters influence loads (customer mix, load drivers, generation mix, building types, etc.), it would be extremely difficult to formulate the physical relationship between the effective capacity of PV and a given utility or substation load.

In practice, the only reliable approach to estimate the effective capacity of PV has been to proceed experimentally through the analysis of a representative sample of hourly (or shorter time step) utility load and time/site coincident PV output data. In an ongoing study by the authors $[2,4,5]$, the effective capacity of PV was determined for a large sample of US utilities, substations, and large customers. The necessary time/site specific PV output data were derived from satellite remote sensing. The accuracy of the satellite-based approach has been reported in [6]. The load studied span several orders of magnitude, from a few $100 \mathrm{~kW}$ to several $\mathrm{GW}$, and cover most US climatic and socio-economic regions (see Fig. 1).

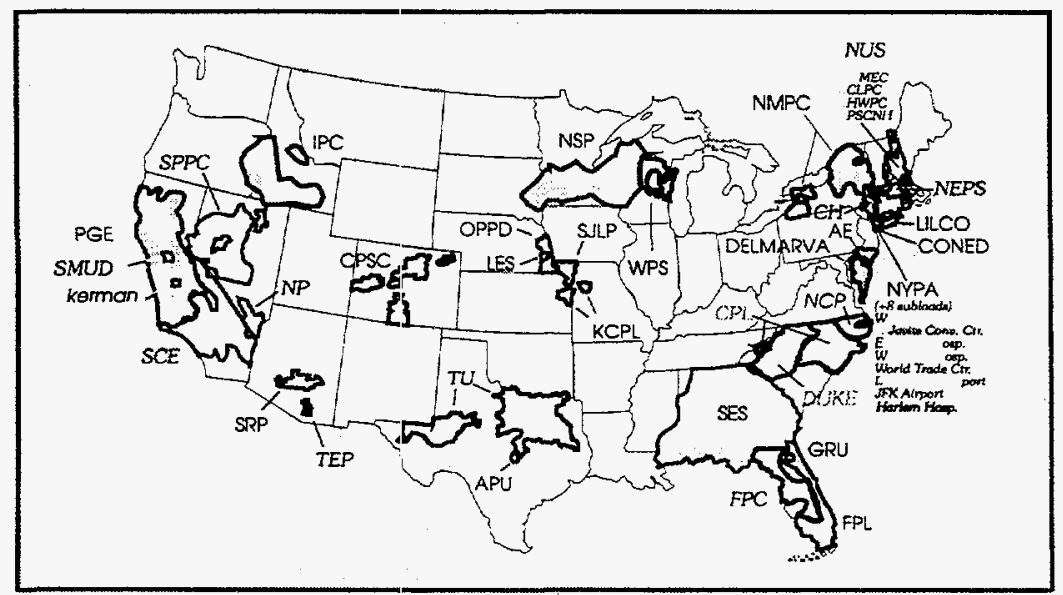

Figure 1: Geographical distribution of test utility, substation, and customer loads 
Two key findings of this work are:

(1) Some of the highest effective capacities are found in regions which have not traditionally been associated with solar energy, in particular, the central US and the eastern sea board;

(2) A well defined relationship was observed between load shapes and effective capacity. This relationship is shown in Fig. 2. The load shape is characterized in terms of its "modified summer-to-winter peak load ratio" (a composite parameter based primarily on the load's summer-to-winter peak load ratio, but also accounting for time of peak, extent of evening shoulder, daily excursion, off-season load and load size).

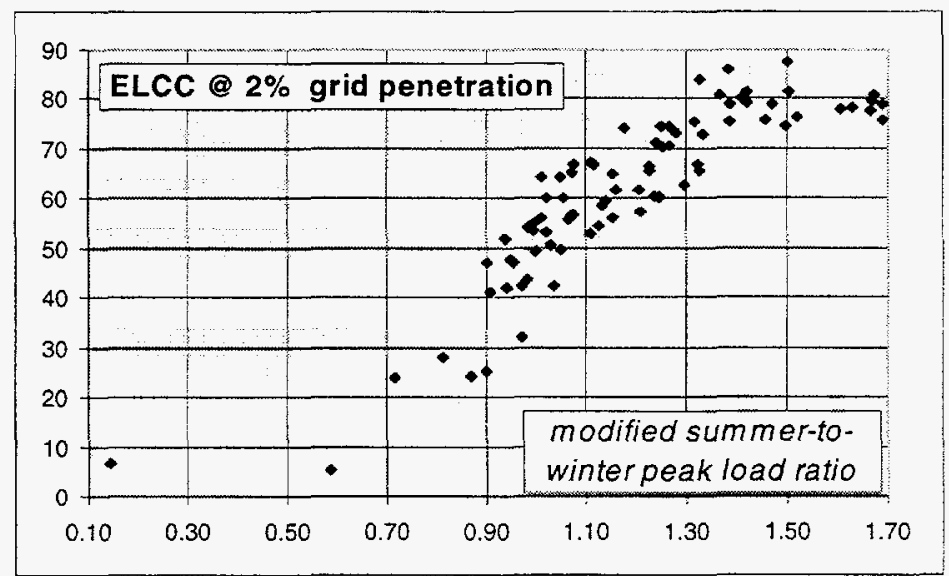

Figure 2: ELCC of PV vs. load shape parameter based on the analysis of 82 utility and substation load-years

By contrast, ELCC was not found to be well correlated with the magnitude of the local solar resource as can be seen in Fig. 3.

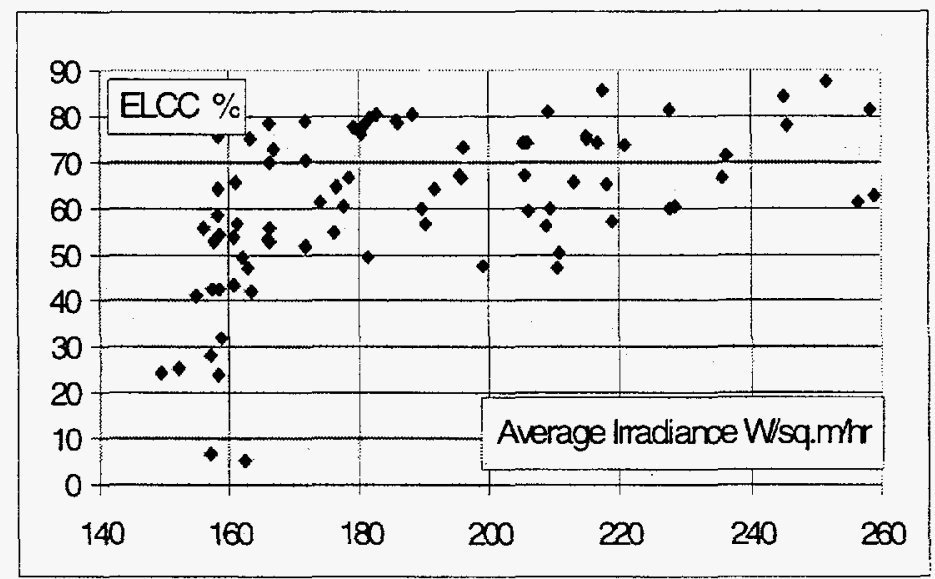

Figure 3: Effective capacity of $P V$ vs. solar resource 


\section{MAPPING PV's EFFECTIVE CAPACITY}

\section{Methods}

The observation that some of the highest effective capacities are found in non-traditional solar regions (and vice-versa) was an incentive to take the issue a step further and to produce a map of PV capacity for the US.

The observation that load characteristics are well correlated with PV's effective capacity provided the tool to accomplish such a task, at least on a preliminary basis.

Input Data: Basic load shape data were obtained for the great majority of US utilities for the year 1993 [7]. The data consist of summer and winter peak loads for over 500 utilities with peak loads in excess of $75 \mathrm{MW}$. Direct application of the relationship observed between the summerto-winter peak load ratio and PV capacity [2], provides an initial estimate of PV's effective capacity for each utility for the year 1993.

Gridding: Utility loads were gridded on a $2^{\circ}$ latitude-by $-2^{\circ}$ longitude map. Each utility was distributed into one or more grid cells, depending on the size and shape of its service territory and the location its major points of use (i.e., large cities). Information on utility service territory was obtained from [8].

The resulting effective capacity of each grid cell was then estimated from a weighted average of utilities (or portion thereof) composing each cell.

A minor measure of smoothing was applied to the gridded map via deterministic interpolation: only about $10 \%$ of the cells with low assigned weight were subjected to such smoothing. Finally, for display purposes, the $2^{\circ}$ resolution map was interpolated into a $1^{\circ}$ resolution map.

\section{Results}

The product of the mapping exercise is shown in Fig. 4. The map features three main regions of high PV capacity:

- The largest region covers the central US from the northwestern great plains and the metropolitan areas of Chicago and Detroit down to the lower Mississippi Valley and, to a lesser extent Texas. The core of this region features the highest capacities observed in the United States.

- The second region includes California, western Arizona, southern Nevada.

- The third region, the smallest geographically but very large in terms of installed utility capacity, spans the eastern metropolitan area extending from North Carolina to Boston. 


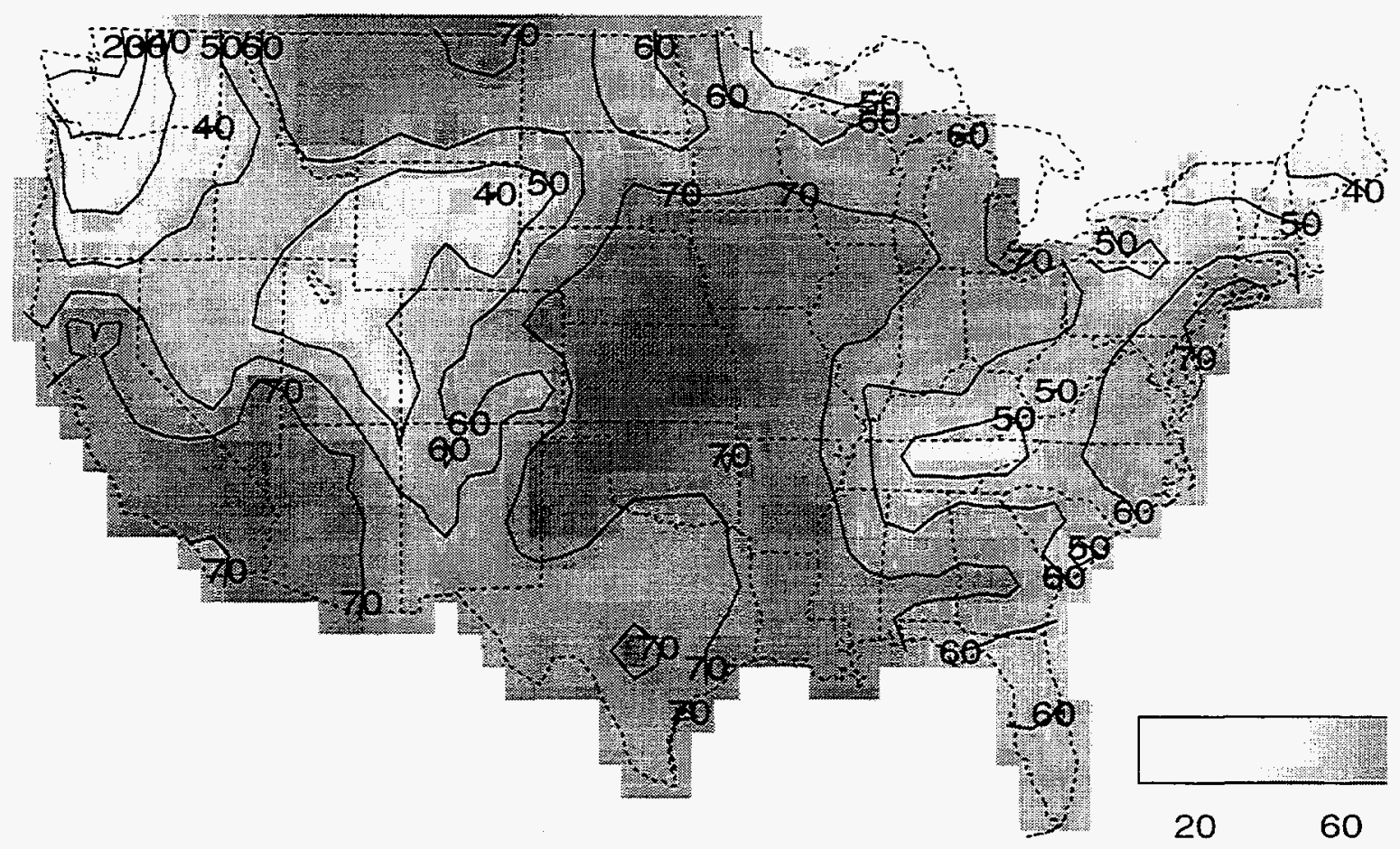

Figure 4: Distribution of PV ELCC in the United States

The features of this map are fully consistent with the partial evidence gathered from the sample utilities shown in Fig. 1, and for which ELCC was formally derived. This is remarkable given the fact that the gridded map was derived solely from load shape data, without solar resource input.

These features confirm our preliminary findings, stating that regions of highest PV effective capacity do not always overlap with regions traditionally associated with solar energy development. For instance, if one compares Fig. 4 with the North American solar resource map shown in Fig. 5, there is for California and Western Arizona, for the Pacific Northwest, the extreme northeast and of the north end of the Great Lakes. However, this is not the case for much of the western US and the extreme southeastern US, two traditional solar regions. There is no overlap either for the northern heartland and the eastern seaboard which had not been considered to be regions of high solar potential

The map does reflect key climatic and socio-economic realities, the combination of which is highly relevant to the effective capacity of PV. The regions of high effective capacity tend to match areas associated with strong summer heat waves (particularly in the case of the central US region). These regions may also be associated with areas where utility demand is driven by commercial air conditioning (particularly in the case of the eastern and western metropolitan regions), and where the electrical heating load is not significant (i.e., absence of cold weather conditions and/or use of other energy sources such as oil or gas).

Beyond this preliminary map: The map in Fig. 4 is based only on 1993 data and could well reflect unusual [climatic or other] circumstances in some areas of the country, although it is doubtful that its overall structure should be questioned, given the consistency with of the present results the partial experimental evidence from 1987 and 1988. Nevertheless, it would be 
important (and relatively straightforward) to repeat the exercise over several years in order to: (1) eliminate the risk of unusual circumstances, (2) observe year-to-year variability, and (3) identify possible trends toward (or away from) increased PV's effective capacity.

Producing maps for other levels of PV penetration, fixed PV systems, and/or other load matching parameters should also be worthwhile efforts. To accomplish these tasks, however, other basic load shape parameters would be necessary beyond the summer and winter peak data used in the present analysis.

Finally, it must be stressed that the resolution of the present map is still very coarse and does not reflect localized opportunities. However, one should agree that a grid cell with high ELCC would translate into many local opportunities and vice-versa. Interested utilities could apply the present methodology to increase spatial resolution and identify high PV capacity areas within their service territory.

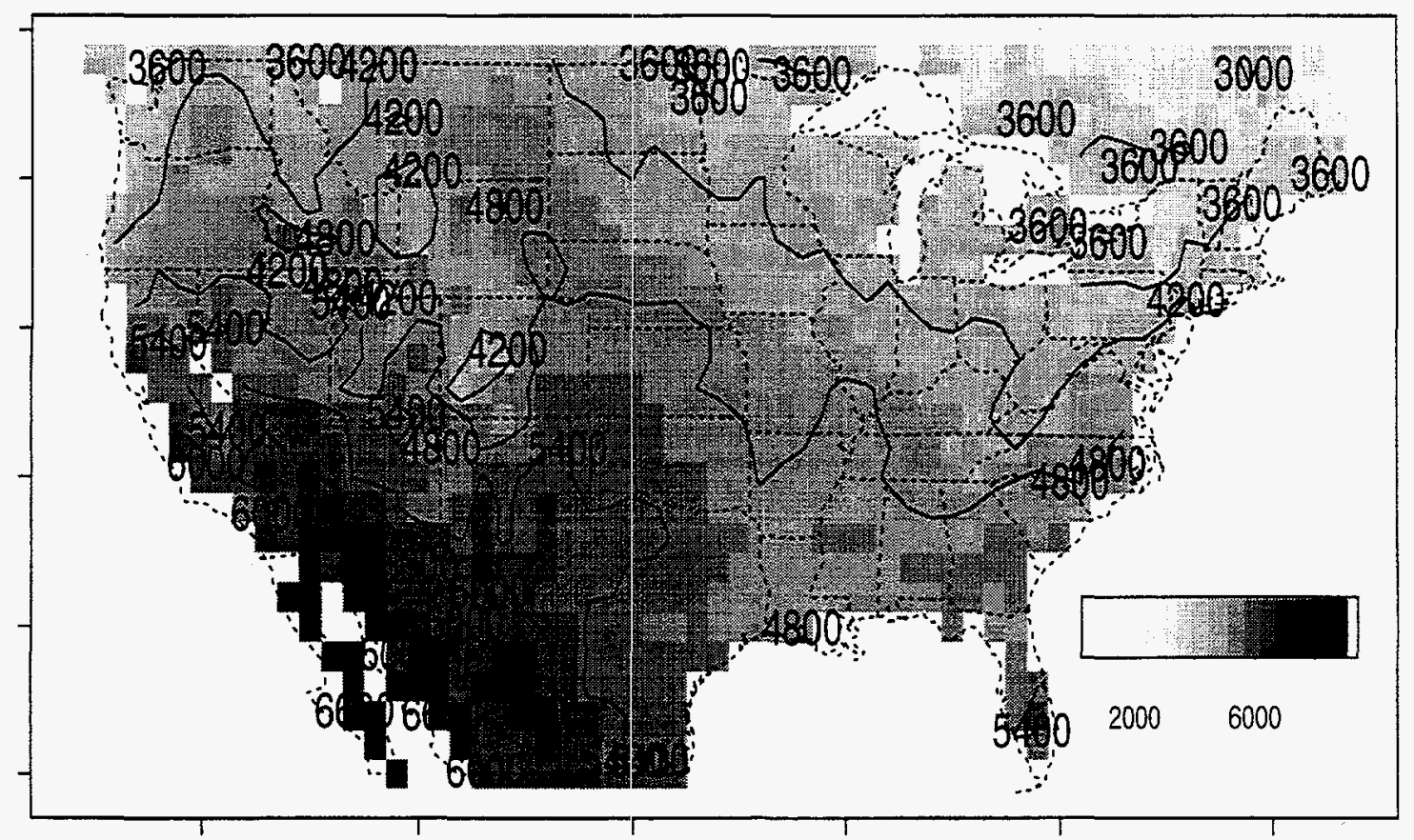

Figure 5: Distribution of solar resource in North America (direct irradiance [2])

\section{CONCLUSIONS}

A map of PV's effective capacity was produced as the result of a logical, multi-step investigative process involving:

- the development and evaluation of a procedure to access time-site specific PV production data from satellite remote sensing,

- the detailed analysis of over 30 test utilities,

- the identification of a well-defined relationship between load shape parameters and PV's effective capacity, and finally, 
- the acquisition of load shape data for the great majority of US utilities.

The map confirms the fragmentary evidence assembled from the test utilities. That is, some of the highest effective capacities are found in regions which had not traditionally been associated with solar energy, in particular, the central US and the eastern seaboard.

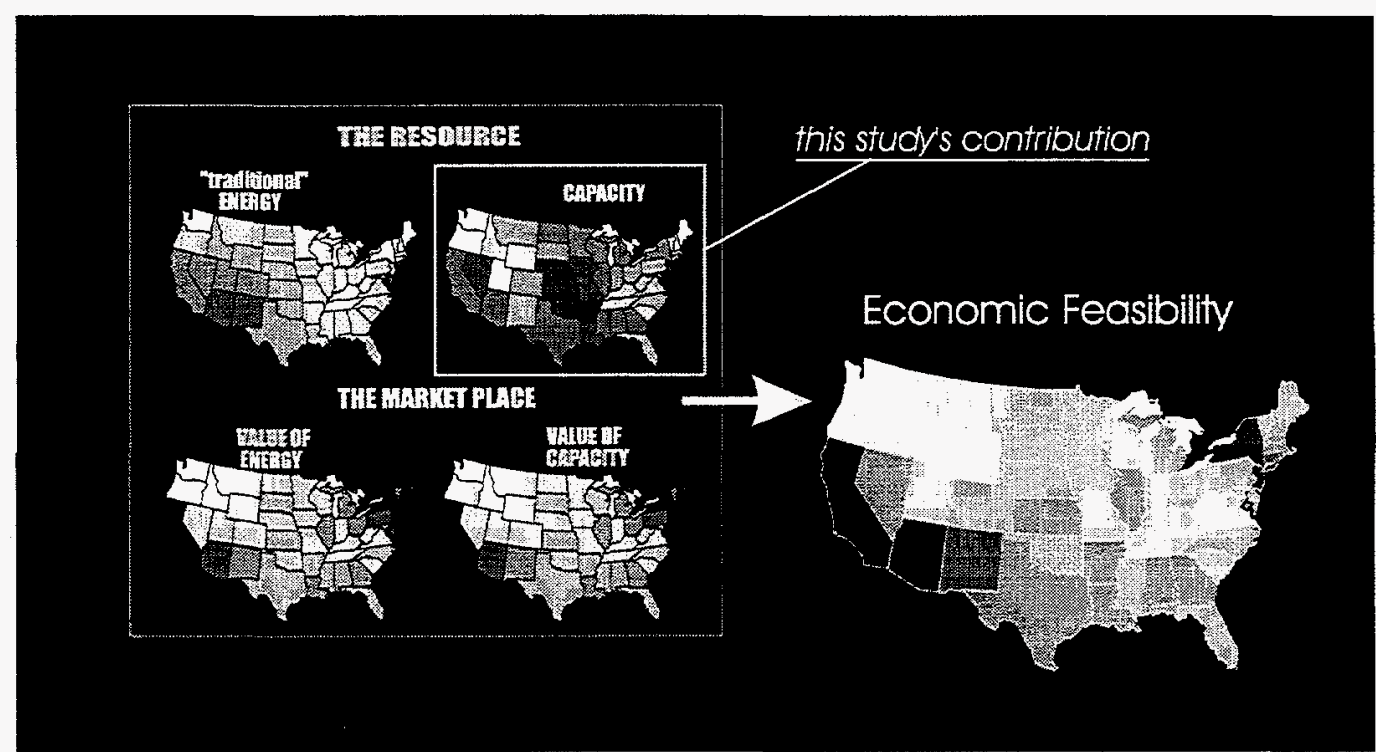

Figure 6: An example of how the information produced in this paper could contribute to a nation-wide assessment of $P V$ development opportunities.

The map should constitute a useful source of information for the economic and technical assessment of PV's opportunity in the US. An example of possible application is sketched in Fig. 6 , merging the present capacity map, and the traditional solar resource (energy) map, with maps of capacity and energy value to identify the distribution of customer-sited grid-connected PV markets.

\section{ACKNOWLEDGMENTS}

This project was undertaken as a part of NREL contract XR-1-11168-1 with Christy Herig as project managers (and before her Roger Taylor and William Wallace). Thanks to David Renné (NREL) and Dan Tarpley (NOAA) for their help throughout the load matching project. Thanks to Mike Bergman and the UPVG staff who played a key role in providing peak load data.

\section{REFERENCE}

1. T. Hoff, D. Shugar, A. Suchard, H. Wenger, K. Lau, G. Ball and J. Mead, (1992): The Photovoltaic Grid Support Project at Kerman Substation -- Project Plan. PG\&E Advanced Energy Systems Report 007.5-92.5 , Pacific Gas and Electric Company San Ramon, California

2. R. Perez, R. Seals and R. Stewart, (1993): Solar Resource -- Utility Load Matching Assessment, Interim Subcontract Report no. NREL/TP-411-6292, NREL, Golden, CO 
3. L. Garver, (1966): Effective Load Carrying Capability of Generating Units. IEEE Transactions, Power Apparatus and Systems, Vol. Pas-85, no. 8

4. R. Perez, R., R. Seals and R. Stewart, (1993): Assessing the Load Matching Capability of Photovoltaics for US Utilities Based Upon Satellite-Derived Insolation Data, IEEE Transactions, pp. 1146-1149 (23d. PV Specialists, Louisville, KY).

5. R. Perez, R. Seals and R. Stewart, (1994): Matching Utility Peak Loads with Photovoltaics, Proc. RENEW-94, (NESEA). Stamford, CT, USA

6. R. Perez, R. Seals, R. Stewart, A. Zelenka and V. Estrada-Cajigal (1994): Using SatelliteDerived Insolation Data for the Site/Time Specific Simulation of Solar Energy Systems Solar Energy Vol. 53,6

7. M. Bergman, (1994): Personal Communication, UPVG, Washington, DC, USA

8. Electrical Utilities of the United States (1990), Electrical World, McGraw-Hill, New York. 


\section{ATTACHMENT No. 2}

Estimating Market Potential for

Reducing Customer Peak Loads through Photovoltaics 


\title{
Estimating Market Potential for Reducing Customer Peak Loads Through Photovoltaics
}

\author{
Joseph Bryan \\ Richard Perez \\ Atmospheric Sciences Research Center \\ University of New York at Albany
}

\section{Abstract}

The ability of photovoltaics (PV) to provide electricity at competitive rates in the near term depends in part on the resource's capability to offset customer peak demands. Using PV to reduce peak customer demand for electricity maximizes the economic potential of the resource by reducing customer demand as well as energy charges. Studies have quantified PV's peak load matching capability on a utility-wide scale. The goal of this paper is to estimate the number of utility customers whose peak loads are well matched with solar availability. We develop a simple tool for estimating the market size of high load matching PV customers and provide illustrative examples of customer owned PV economics. We show that (1) the market size of high load matching PV applications on the customer scale is significant even within utility systems whose load requirements are not particularly well matched with $P V$; and (2) the cost of PV as a peak shaving resource for utility customers is approaching competitive levels.

\section{Introduction}

The near term economic viability of photovoltaics (PV) depends in part on the resource's ability to act as a peak-shaving device for utility customers. Time of day energy rates and seasonal demand rates often reflect this reality. Using PV to offset peak loads maximizes the economic potential of PV by reducing customer demand as well as energy charges. The effectiveness of PV in this respect depends on how well the solar resource matches customer peak demand periods.

Studies have quantified the match between PV output and utility peak loads. This paper focuses on the customer scale. A simple tool based on the utility scale load-PV match is developed to estimate the market size of customer scale PV applications with high loadPV matches. Site specific examples of customer side economic analysis are provided to illustrate the near term economic potential of PV as a peak shaving resource. 


\section{Capacity Value of Photovoltaics}

Because it is not a dispatchable resource, photovoltaics has traditionally been assigned low or no capacity credit. Quantifying the load matching capability of PV is important because this parameter is relevant to the value of the PV resource.

Analysis of actual utility loads and coincident PV output have shown that there is often a substantial degree of correlation between utility peak loads and the availability of the solar resource (Perez et al., 1993). This relationship was found to be largely independent of the overall magnitude of the solar resource; instead the relationship was found to strongly relate to a utility's summer to winter peak load ratio (Perez 1993).

Utilities with large summer commercial air conditioning loads and low levels of electric heating in winter have shown the strongest relationship between peak loads and solar availability. Thus, many high value PV applications have been found to lie outside the traditional solar energy regions of Florida and the Southwest. Using the effective load carrying capability (ELCC) as an indicator of PV's ability to meeting utility peak demands, it has been possible to estimate the value of the resource on the utility scale. The need to identify high value PV applications within a utility system remains.

\section{Use of the Effective Load Carrying Capability (ELCC)}

Effective Load Carrying Capability (ELCC) of a generating unit was originally defined by Garver as the additional load that a utility system can deliver as the result of the additional generating unit, taking into account the system's loss of load probability, installed reserves, and the new unit's forced outage rate (Garver, 1966). The use of ELCC was generalized (Perez et al., 1993) to characterize only the load-resource relationship. This allowed the ELCC measure to be extended to any type of load. The determination of a resource's ELCC helps to determine the capacity value of the resource within the overall utility system.

\section{Methodology}

ELCC was estimated for over 500 utilities based on the strong relationship between sample load shape parameters and ELCC (Perez, 1995). The ELCC data are representative of the load carrying capability of PV at a modest penetration level on the utility grid for a one axis tracking PV array.

A probability distribution of utility PV ELCC in the United States was constructed. A beta distribution was fitted to the data (figure 1). ${ }^{1}$

1 The correlation coeficient between the transformed utility data and the beta distribution is .999 . 


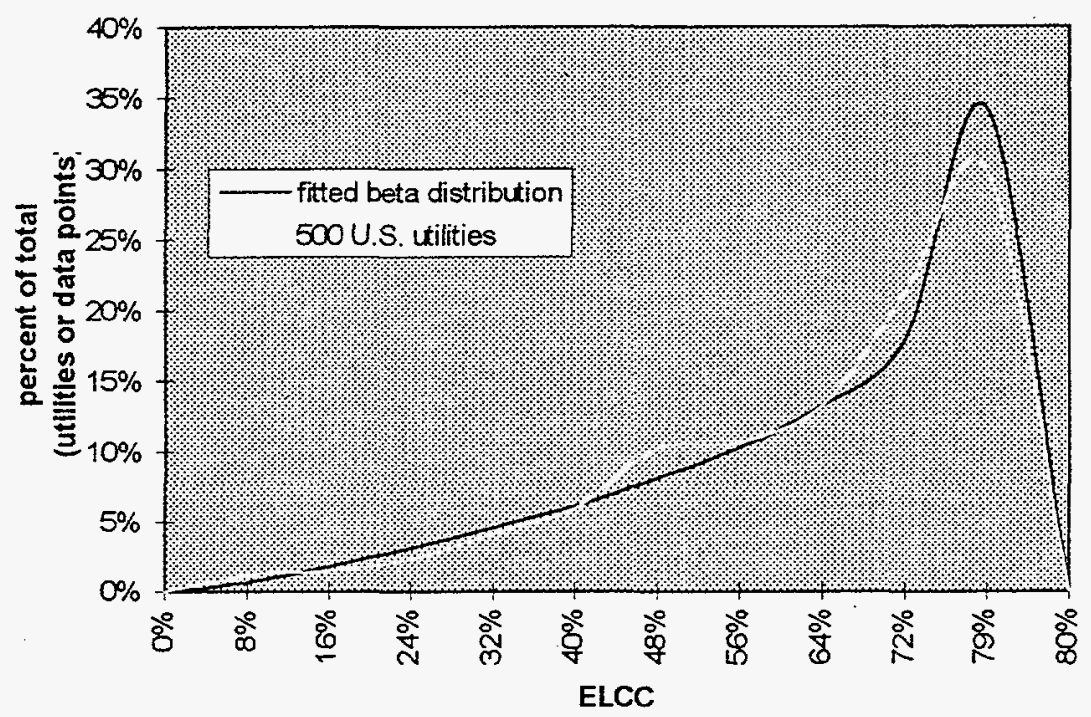

figure 1: Probability Distribution of Transformed Utility ELCC Data and Beta Distribution with Equivalent Mean

The beta function is commonly used to study the variation in the percentage of a variable across samples, such as utility ELCCs (McFarlane, 1950) The function is represented by the density:

$$
f(x)=\frac{(a+B+1) !}{a ! B !} \times(1-x)=0
$$

The mean ELCC for the 500 utilities is about $60 \%$. A series of similar beta distributions were derived to represent ELCC distribution for other mean values. Assuming self similarity between the ensemble of U.S. utilities and the ensemble of substations and large customers within a utility, these distributions are used to model the distribution of customer ELCC within a particular utility, given the utility-wide ELCC. This relies on two assumptions.

1) The distributions of utility-level ELCCs and utility customer ELCCs are self similar. That is, the distributions will remain similar despite the differences in the scale of the variables (e.g. see Mandelbrot).

2) The expected value of the beta distribution is the ELCC of a particular utility.

The customer distributions were derived from beta functions with standard deviations equal to that shown in figure 1 and expected values ranging from $10 \%$ to $70 \%$. The resulting beta distributions (figure 2 ) estimate the percentage of a particular utility's 
customers that can be expected to have high ELCCs for PV. Using ELCC as an input to measure of the value of a resource to a utility, the distributions also estimate the market size of high value PV applications within a utility system (figure 3).

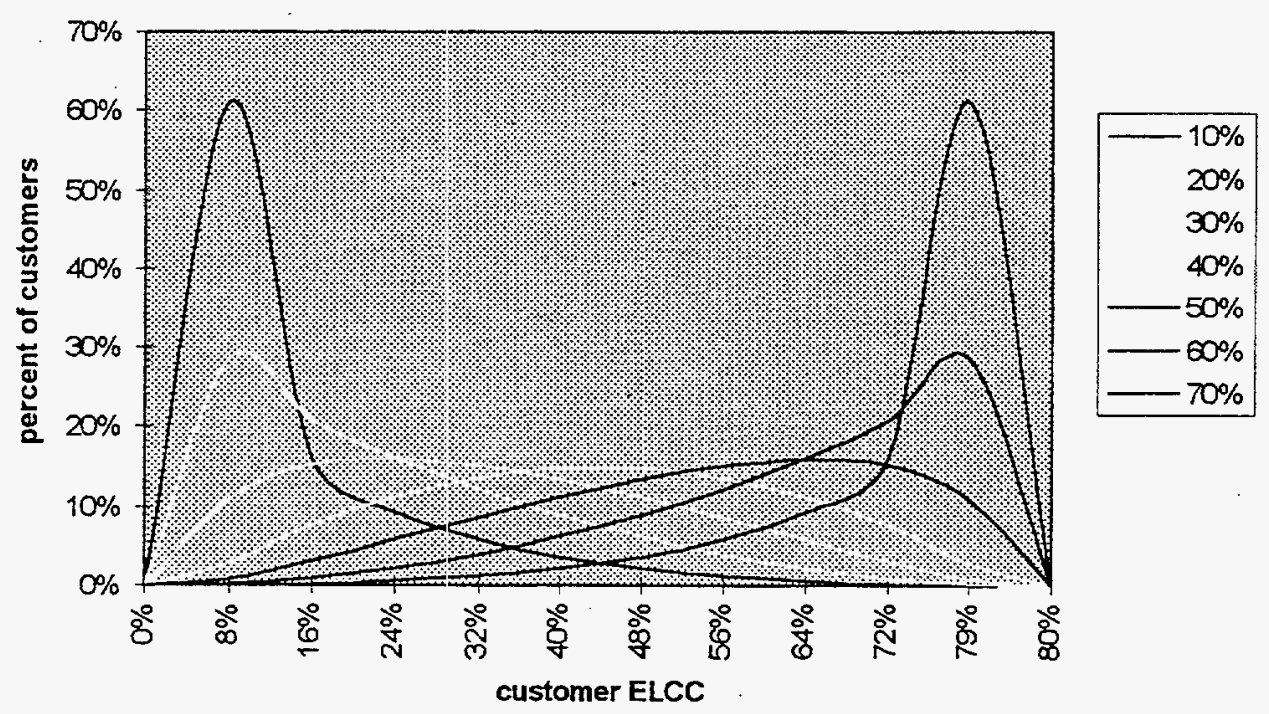

figure 2: Beta Probability Distribution of Utility Customer ELCC (knowing utility-wide ELCC)

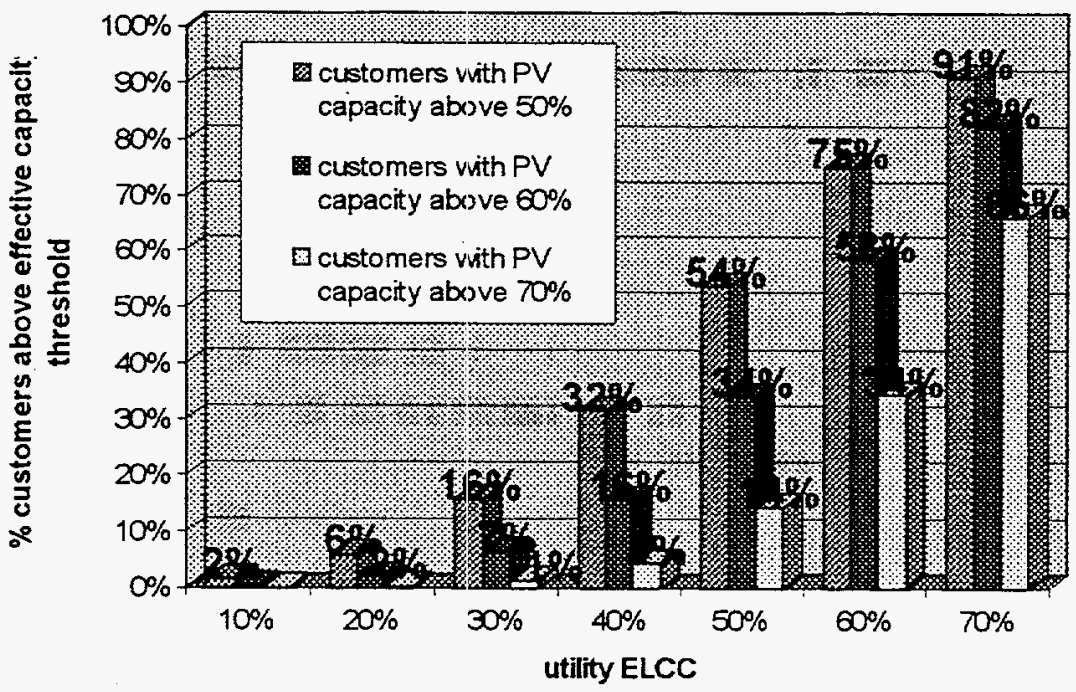

figure 3: Market Share of High PV Capacity Customers as a Function of Utility-Wide PV ELCC 


\section{Application of findings}

Having estimated the market size of high ELCC PV customers, a customer side economic analysis of an investment in PV was completed.

A life cycle model was developed to estimate the costs and benefits for a customer investing in PV. The rate structures of several utilities along with tax incentives of individual states were modeled to determine the economic viability of PV as a demandside resource at current and projected PV and electricity costs. A list of assumptions for the economic analysis is contained in appendix A. Chart 1 shows the benefit-cost ratio of a customer investment in a PV-DSM system with a 70\% customer effective capacity. Based on our findings, over $70 \%$ of Con Edison customers, 34\% of Duke Power customers, $36 \%$ of Salt River Project customers and $4 \%$ of Portland General Electric customers would be in this categary. Chart 2 shows the benefit cost ratio of a PV-DSM system with an ELCC of zero.

Chart 1 reinforces to point that PV's potential is not limited to traditional solar energy regions. The benefit/cost ratios of Con Edison in New York and Salt River Project in Arizona are comparable at $\$ 7.50 /$ watt for PV. However, benefit/cost ratio of a Con Edison customer reaches 1.00 at $\$ 5.00$ /watt while the cost of a PV-DSM system must be $\$ 4.25 /$ watt for the benefit/cost ratio a Salt River Project customer to arrive at the same level. The power provided by the PV-DSM system is peak power, allowing the customer to capture both demand and energy savings. Because Con Edison has relatively high demand charges the power provided by the PV-DSM system replaces more expensive power for a Con Edison customer than it does for a customer of the Salt River Project.

Chart 1: PV captures capacity credit

\begin{tabular}{|c|c|c|c|c|}
\hline \multicolumn{2}{|c|}{ ConEdison } & \multicolumn{2}{|c|}{ Duke Power } & \\
\hline$\$ / W$ & b/c ratio & $\$ / w$ & b/c ratio* & \\
\hline$\$ 7.50 / w$ & 0.88 & $\$ 7.50 / w$ & 0.93 & \\
\hline$\$ 5.00 / \mathrm{W}$ & 1 & $\$ 5.00 / w$ & 1.08 & \\
\hline$\$ 2.50 / w$ & 1.37 & $\$ 2.50 / w$ & 1.37 & \\
\hline \multicolumn{2}{|c|}{ break-even system cost $\$ 5.00 \mathrm{M}$} & \multicolumn{3}{|c|}{ break-even system cost $\$ 6.00 / \mathrm{w}$} \\
\hline \multicolumn{2}{|c|}{ Portland GE } & \multicolumn{2}{|c|}{ Salt River Project } & \\
\hline$\$ / w$ & b/c ratio & $\$ / w$ & b/c ratio & \\
\hline$\$ 7.50 / w$ & 0.69 & $\$ 7.50 / w$ & 0.83 & \\
\hline$\$ 5.00 / \mathrm{W}$ & 0.73 & $\$ 5.00 / w$ & 0.94 & \\
\hline$\$ 2.50 / \mathrm{w}$ & 0.85 & $\$ 2.50 / w$ & 1.23 & \\
\hline \multicolumn{2}{|c|}{ break-even system cost $\$ 1.50 / \mathrm{w}$} & \multicolumn{3}{|c|}{ break-even system cost $\$ 4.25 / \mathrm{w}$} \\
\hline
\end{tabular}


Chart 2: PV is given no capacity credit

\begin{tabular}{|c|c|c|c|c|}
\hline \multicolumn{2}{|c|}{ ConEdison } & \multicolumn{2}{|c|}{ Duke Power } & \\
\hline$\$ / w$ & b/c ratio & $\$ / W$ & b/c ratio* & \\
\hline$\$ 7.50 / w$ & 0.72 & $\$ 7.50 / w$ & 0.86 & \\
\hline$\$ 5.00 / \mathrm{w}$ & 0.77 & $\$ 5.00 / w$ & 0.98 & \\
\hline$\$ 2.50 / \mathrm{w}$ & 0.92 & $\$ 2.50 / w$ & 1.19 & \\
\hline \multicolumn{2}{|c|}{ break-even system cost $\$ 2.00 / \mathrm{w}$} & \multicolumn{3}{|c|}{ break-even system cost $\$ 4.75 / \mathrm{W}$} \\
\hline \multirow{2}{*}{\multicolumn{2}{|c|}{ Portland GE }} & \multirow{2}{*}{\multicolumn{2}{|c|}{ Salt River Project }} & \\
\hline & & & & \\
\hline$\$ / W$ & b/c ratio & $\$ / W$ & $\mathrm{~b} / \mathrm{c}$ ratio & \\
\hline$\$ 7.50 / w$ & 0.67 & $\$ 7.50 / w$ & 0.8 & \\
\hline$\$ 5.00 / \mathrm{w}$ & 0.71 & $\$ 5.00 / w$ & 0.89 & \\
\hline$\$ 2.50 / w$ & 0.8 & $\$ 2.50 / w$ & 1.14 & \\
\hline
\end{tabular}

* Figure includes North Carolina's $35 \%$ tax credit for commercial investments in photovoltaics (General Assembly of North Carolina, 1993).

\section{Conclusions}

It has been assumed that most high value PV-DSM sites lie within utility systems with high ELCCs. Using the derived beta distributions of utility customers reveals that the market size of high value PV customers (or alternatively, the number of bigh load-PV match substations) may remain significant even within utility systems of marginal to low utility level ELCCs. This finding is encouraging because it shows that the overall market size for PV as a peak shaving resource may be larger than previous estimates. For example, Figure 2 shows that more than $14 \%$ of the customers of a utility with an ELCC of $50 \%$ have effective load carrying capabilities of $70 \%$ or greater.

The ability of PV to offset electricity demands during peak periods allows customers to capture both energy and demand savings. A customer's ELCC is an effective measure of this ability. The near term economic potential for PV as a peak shaving investment appears promising for customers with high ELCCs. Many of these high value PV applications lie outside traditional solar energy regions of Florida and the Southwest. In fact, strong market potential exists for PV as a peak shaving resource in the Northeast. Many customers in this region of the country have peak loads driven by the need for air conditioning and have high utility demand and energy costs. For example, at current system cost, the economic benefits cover nearly $90 \%$ of the costs of a PV-DSM system for a Con Edison customer with an ELCC of $70 \%$. 


\section{Appendix A}

\begin{tabular}{|c|c|c|}
\hline System Data & & Customer Data \\
\hline Array Size $(\mathrm{kW})$ & 100 & Federal Tax Credits $|\%|$ \\
\hline Equipment Lif (years) & 30 & $\begin{array}{l}\text { State Tax Credit (\%) } \\
\text { Loan Lite (years) }\end{array}$ \\
\hline ELCC $\{\% \mid$ & $70.00 \%$ & Depreciation Life (yoars) \\
\hline Rato Escalation & $4.53 \%$ & Interest Rate $(\%)$ \\
\hline O\&MRate $(\$ / k W h)$ & 0.0100 & Customer Federal Income TaxRate (\% \\
\hline \multirow[t]{4}{*}{ O\&MEscalation (\%) } & $3.58 \%$ & Customer State Income TaxRate $|\%|$ \\
\hline & & Effective State TaxRato (\%) \\
\hline & & Customar Dis count Rate (\%) \\
\hline & & Rebato to Customer(\$) \\
\hline Installed Array Cost ( $\$ / \mathrm{kW})$ & $\$ 7,500.00$ & Customer's investod Equity $(\%)$ \\
\hline Total Capital Costs (\$) & $\$ 750,000.00$ & Loan Amount \\
\hline
\end{tabular}

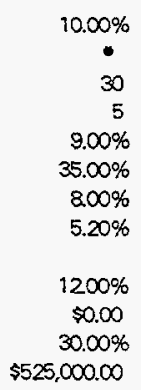

* 35\% for North Carolina, $0 \%$ for New York, Arizona and Washington

\section{Acknowledgments}

This work was conducted as a byproduct of the National Renewable Energy Laboratory's Solar Resource Utility Load Matching Project (subcontract XR-1-11168-1). The authors would like to thank Jerrold Oppenheim of Renewable Energy Technology Analysis at Pace University School of Law and Steven Letendre of the Center for Energy and Environmental Policy at the University of Delaware for their assistance with the analysis on this project.

\section{References}

L. Garver, (1966): Effective Load Carrying Capability of Generating Units. IEEE Transactions; Power Apparatus and Systems. Vol. Pas-85, no. 8.

A. McFarlane, (1950): An Introduction to the Theory of Statistics, McGraw-Hill, New York, NY.

B.B. Mandelbrot, (1982): The Fractal Geometry of Nature. W.H. Freeman \& Co., New York, NY.

General Assembly of North Carolina, (1993): (G.S. 105-130.32) Credit against corporate income tax for installation of solar energy equipment for the production of heat or electricity in certain processes.

R. Perez and R. Seals, (1995): Geographical Distribution of Photovoltaic Effective Capacity in the United States, Proc. ASES Annual Meeting, Minneapolis, MN.

R. Perez, R. Seals and R. Stewart, (1993): Solar Resource--Utility Load Matching Assessment, Interim Subcontract Report no. NREL/TP-411-6292, NREL, Golden, CO. 
R. Perez, R. Seals and R. Stewart, (1993): Assessing the Load Matching Capability of Photovoltaics for U.S. Utilities Based Upon Satellite-Derived Insolation Data, IEEE Transactions, pp.1146-1149 (23cl. PV Specialists, Louisville, KY).

R. Perez, R. Seals and R. Stewart, (1994): Matching Utility Peak Loads with Photovoltaics, Proc. RENEW-94, (NESEA), Stamford, CT. 